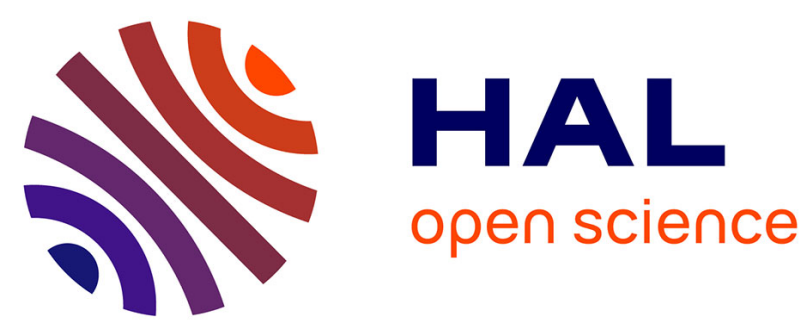

\title{
Formation of the Ce-Nd mantle array: crustal extraction vs. recycling by subduction
}

\author{
Claudine Israel, M. Boyet, R. Doucelance, P. Bonnand, P. Frossard, D.
}

Auclair, A. Bouvier

\section{- To cite this version:}

Claudine Israel, M. Boyet, R. Doucelance, P. Bonnand, P. Frossard, et al.. Formation of the Ce-Nd mantle array: crustal extraction vs. recycling by subduction. Earth and Planetary Science Letters, 2020, 530, pp.115941. 10.1016/j.epsl.2019.115941 . hal-02409422

\section{HAL Id: hal-02409422 \\ https://hal.science/hal-02409422}

Submitted on 13 Dec 2019

HAL is a multi-disciplinary open access archive for the deposit and dissemination of scientific research documents, whether they are published or not. The documents may come from teaching and research institutions in France or abroad, or from public or private research centers.
L'archive ouverte pluridisciplinaire HAL, est destinée au dépôt et à la diffusion de documents scientifiques de niveau recherche, publiés ou non, émanant des établissements d'enseignement et de recherche français ou étrangers, des laboratoires publics ou privés. 

subduction

Clermont-Ferrand, France.

${ }^{\mathrm{b}}$ Department of Earth Sciences, University of Western Ontario, Canada.

${ }^{\mathrm{c}}$ Bayerisches Geoinstitut, Universität Bayreuth, Germany.

*Corresponding author.

13 E-mail address: claudine.israel@uca.fr (Claudine Israel).

\section{ABSTRACT}

We present new measurements of ${ }^{138} \mathrm{Ce} /{ }^{142} \mathrm{Ce}$ and ${ }^{143} \mathrm{Nd} /{ }^{144} \mathrm{Nd}$ isotopic ratios in terrestrial and extraterrestrial samples. The mean value obtained from nine chondrites defines the ${ }^{138} \mathrm{Ce} /{ }^{142} \mathrm{Ce}$ ratio of the chondritic uniform reservoir (CHUR) as $0.02256577 \pm 66$ (2sd). MORBs and OIBs define the mantle array in the $\varepsilon \mathrm{Nd}$ vs. $\varepsilon \mathrm{Ce}$ diagram to be $\varepsilon \mathrm{Nd}=-7.3( \pm 0.5) \times \varepsilon \mathrm{Ce}+0.4( \pm 0.3)$. From MORB measurements, we derive the isotopic composition of the depleted MORB mantle (DMM) to be $\varepsilon \mathrm{Ce}=$ -

$211.1 \pm 0.6(2 \mathrm{sd})$. Both CHUR and a modelled early-depleted mantle reservoir plot on the mantle array.

22 Thus, the precise determination of the mantle array does not further constrain the $\mathrm{La} / \mathrm{Ce}$ and $\mathrm{Sm} / \mathrm{Nd}$ ratios of the bulk silicate Earth (BSE; i.e., primitive mantle). The composition of $1.8 \mathrm{Ga}$ upper continental crust obtained from aeolian sediments is $\varepsilon \mathrm{Ce}=1.8 \pm 0.3(2 \mathrm{sd} ; \varepsilon \mathrm{Nd}=-11.2)$, and that of its $2.2 \mathrm{Ga}$ equivalent is $\varepsilon \mathrm{Ce}=2.3 \pm 0.3(2 \mathrm{sd} ; \varepsilon \mathrm{Nd}=-17)$. Binary mixing models between depleted (DMM) and enriched (upper crust or mafic crust composition) components do not reproduce the linear Ce-Nd mantle array but plots close to the island arc basalt data. When the bulk Ce isotopic composition of the 
continental crust is calculated from the range of accepted $\mathrm{Nd}$ isotope values and a mass-balance budget of the BSE, the mixing curves are closer to the mantle array. However the calculated Ce isotopic composition for the bulk crust is always less radiogenic than measurements. Adjusting the Ce-Nd isotopic composition or the $\mathrm{Ce} / \mathrm{Nd}$ ratio of the end-members to fully linearise the mixing curve leads to unrealistic values never measured in terrestrial samples. We propose a recycling model to reconstruct the mantle array with the participation of both oceanic crust and sediments in the mantle through time. Cerium is a redox sensitive element, making the La-Ce and Sm-Nd systematics an ideal combination to investigate sediment recycling through time. In this recycling model, the most extreme EM-like signatures require the involvement of oceanic sediments that formed under reduced conditions before the Great Oxygenation Event at $2.4 \mathrm{Ga}$, and which are devoid of Ce elemental anomalies.

Keywords: ${ }^{138} \mathrm{Ce} /{ }^{142} \mathrm{Ce}$; rare earth elements; chondritic bulk silicate Earth; silicate reservoirs; mantle array; ocean island basalts.

\section{Introduction}

Long-lived isotope systematics are remarkable tracers of the long-term evolution of the different terrestrial reservoirs. Radiometric systems based on refractory lithophile elements are the most likely to provide robust information on the bulk silicate Earth (BSE) because they were not lost during Earth's accretion or segregated into the core during its differentiation. Indeed, rare earth elements (REEs) have high condensation temperatures and remain strictly lithophile at the conditions of Earth's core formation (Bouhifd et al., 2015). The REE concentrations of the primitive mantle (PM) are assumed to be equivalent to those of the BSE, and their ratios should be chondritic if chondrites are the Earth's main building blocks. Boyet and Carlson (2005) identified a systematic offset between the ${ }^{142} \mathrm{Nd} /{ }^{144} \mathrm{Nd}$ ratios

53 of modern terrestrial rocks and chondrites resulting in an active debate on the refractory lithophile 54 element composition of the PM (see Caro et al., 2008; Jackson and Jellinek, 2013; O'Neill and Palme, 
2008). ${ }^{142} \mathrm{Nd}$ is a radiogenic isotope partly produced by the decay of ${ }^{146} \mathrm{Sm}\left(\mathrm{T}_{1 / 2}=103 \mathrm{Ma}\right)$. Variations in the ${ }^{142} \mathrm{Nd}$ abundances exist among Solar System materials and they reflect isotopic heterogeneities within the protoplanetary disk (Bouvier and Boyet, 2016; Burkhardt et al., 2016). Determining terrestrial variations relative to chondrites thus requires precise knowledge of the nature of Earth's building blocks. Isotopic similarities between terrestrial samples and enstatite chondrites (ECs) suggest this group of chondrites to be the main terrestrial component (Dauphas, 2017; Javoy, 1995). The mean EC ${ }^{142} \mathrm{Nd} /{ }^{144} \mathrm{Nd}$ value is nevertheless lower than that of the BSE without distinguishable variations in their nonradiogenic Nd isotopic compositions from Earth (Burkhardt et al., 2016; Boyet et al., 2018). Variations in ${ }^{142} \mathrm{Nd} /{ }^{144} \mathrm{Nd}$ values between different EC subgroups show further that the EL3 subgroup matches the terrestrial value (Boyet et al., 2018). These results remove the need of an early fractionation of the $\mathrm{Sm} / \mathrm{Nd}$ ratio of the Earth if the Earth was purely made of EL3 materials. The EL3 chondrites are nevertheless problematic in regards to the elemental composition (e.g. $\mathrm{Mg} / \mathrm{Si}$ ) of the bulk Earth.

This study presents measurements of two long-lived isotopic systems in which both the parent and daughter elements are REEs. ${ }^{138} \mathrm{La}$ decays into ${ }^{138} \mathrm{Ce}$ by beta emission $\left(t_{1 / 2, \beta}=295.5\right.$ Gyr: Tanimizu, $2000)$ and into ${ }^{138} \mathrm{Ba}$ by electron capture, whereas ${ }^{147} \mathrm{Sm}$ decays into ${ }^{143} \mathrm{Nd}$ by alpha emission $\left(t_{1 / 2, \alpha}=106\right.$ Gyr: Begemann et al., 2001). Variations of ${ }^{138} \mathrm{Ce} /{ }^{142} \mathrm{Ce}$ ratios are expected to be small due to the long half-life and low abundance $\left(0.09 \%\right.$ of total La) of ${ }^{138} \mathrm{La}$. The latest generation of thermal ionisation mass spectrometers (TIMS) can achieve long-term analytical errors below $30 \mathrm{ppm}$ on ${ }^{138} \mathrm{Ce} /{ }^{142} \mathrm{Ce}$ (Bonnand et al., 2019), allowing characterisation of Ce isotopic variations in terrestrial and extraterrestrial materials. Here we present analyses of 11 chondrites (ordinary, enstatite, and carbonaceous) that we use to estimate the Ce isotopic composition of the chondritic uniform reservoir (CHUR). We also redefine the Ce-Nd mantle array based on previous and new measurements including seven mid-ocean ridge basalts (MORBs) and 51 ocean island basalts (OIBs). Lastly, we report the first Ce-Nd isotopic compositions of loess samples as a proxy for the upper continental crust (UCC).

Dickin (1987) first used the Ce-Nd isotopic correlation defined by OIBs to estimate the Ce isotopic composition of the BSE. His regression intercepts the CHUR Nd isotopic composition at a BSE Ce isotopic composition that is $60 \mathrm{ppm}$ less radiogenic than the CHUR value defined by Shimizu et al. 
(1984). However, new results from chondrites and mantle-derived samples lead to a different observation. The mantle array passes directly through the CHUR composition in the Ce-Nd isotopic diagram (Willig and Stracke, 2019). Our new results first confirm this trend. Moreover we show that a modelled reservoir depleted in incompatible elements (and characterised by a depleted REE pattern; see early-depleted reservoir in Boyet and Carlson, 2005) that would be formed early in the Solar System's history also plots on the mantle array.

The mantle array must reflect the formation of the major silicate reservoirs and their interactions during Earth's history. Important questions have been addressed by coupling Lu-Hf and Sm-Nd isotope systematics; for example, arc lavas do not follow the Hf-Nd mantle array, which reflects the elevated ${ }^{176} \mathrm{Hf} /{ }^{177} \mathrm{Hf}$ signature measured in most oceanic sediments (Carpentier et al., 2009). Also, the presence of pelagic sediments in the source of the Hawaiian hotspot was first identified from Hf-Nd isotopic measurements (Blichert-Toft et al., 1999). Cerium is a redox sensitive element, making the La-Ce and Sm-Nd systematics an ideal combination to investigate sediment recycling through time. Indeed, most documented modern forearc sediments are depleted in Ce relative to neighbouring elements (Plank, 2014). Before the Great Oxygenation Event (GOE), however, all REEs should have behaved similarly and no Ce fractionation is expected to have occurred during that time. Coupling $\mathrm{Ce}$ and $\mathrm{Nd}$ isotopic measurements will thus provide additional constraints on the nature of sediments recycled into the deep mantle and sampled via hotspot volcanism. Chauvel et al. (2008) explained the Hf-Nd mantle array by the recycling of oceanic crust and sediments into the mantle. Here, we present similar models in Ce-Nd isotope diagrams for the first time.

\section{Sample selection}

We measured the Ce and $\mathrm{Nd}$ isotopic compositions of four ordinary chondrites, six enstatite chondrites, one carbonaceous chondrite, seven MORBs, 51 OIBs, one intraplate continental volcanism occurrence (Ethiopia), and six loess samples. To include all mantle end-members, we selected rocks with extreme 
$111 \mathrm{Nd}-\mathrm{Sr}-\mathrm{Pb}-\mathrm{He}$ compositions. OIB samples were selected from 13 locations covering the Atlantic

112 (Iceland, São Miguel (Azores archipelago), Cape Verde, Saint Helena, Tristan Da Cunha), Pacific 113 (Hawaii, MacDonald seamount, Rurutu and Tubuai Islands (Austral archipelago), Fangataufa (Tuamotu 114 archipelago), Tahaa Island (Society archipelago)), and Indian Oceans (Heard, Kerguelen, Reunion and 115 Saint-Paul Island (French Southern and Antarctic Lands)). MORB samples are unaltered glasses 116 collected on the Pacific ridge (Bellot et al., 2015) and the Southwest Indian Ridge. The Pacific MORBs 117 have similar REE patterns and do not show the Dupal anomaly ( $\mathrm{Sr}$ and $\mathrm{Pb}$ isotopic anomalies in MORBs 118 and OIBs erupted around $30^{\circ} \mathrm{S}$ ). We used loesses from western Europe (wind-transported periglacial 119 deposits), China and Tajikistan (sediments originating in northwestern Mongolia and the Karakum 120 (Turkmenistan) and Kyzylkum deserts (Kazakhstan and Uzbekistan), respectively), and the Sahara 121 Desert (dusts blown to Southern France; Chauvel et al., 2014 and references therein; Supplementary data 1, Figs S1-4).

\section{Analytical procedures}

\subsection{Dissolution and chromatography protocols}

All samples were entirely processed at the Laboratoire Magmas et Volcans (LMV, Clermont-Ferrand,

129 France), except three chondrites (NWA 8007, NWA 10854, and Adrar Bous) that were dissolved at the

130 University of Western Ontario (UWO). Mantle-derived and loess samples were dissolved using the 131 following protocol. We used 50 to $300 \mathrm{mg}$ of sample depending on the REE concentration and the 132 quantity of powder available. Powders were digested in a $3: 1$ mixture of $\mathrm{HF}(65 \%)$ and $\mathrm{HNO}_{3}(48 \%)$ 133 that was maintained at $75^{\circ} \mathrm{C}$ on a hot plate for $48 \mathrm{~h}$. Once dried, the samples were dissolved a second 134 time in $6 \mathrm{M} \mathrm{HCl}$. The dissolution protocol was slightly different for chondrites. Oudiyat Sbaa, Yilmia, 135 Pillistfer, Agen, Sahara 97158, and Saint-Séverin were dissolved in a 10:1 mixture of HF (65\%) and $136 \mathrm{HNO}_{3}(48 \%)$ in PFA-Savillex beakers placed on a hot plate at $110{ }^{\circ} \mathrm{C}$ for seven days. Fluorides were 137 broken down in a second step using concentrated $\mathrm{HClO}_{4}$. Allende, Sahara 97072, Adrar Bous, NWA 
8007, and NWA 10854 were dissolved in Parr bombs using the same acid mixtures (48 hours at $180{ }^{\circ} \mathrm{C}$

139 in $\mathrm{HF}-\mathrm{HNO}_{3}$, or seven days at $150^{\circ} \mathrm{C}$, followed by $\mathrm{HClO}_{4}$ treatment). Once dried, all chondrite samples

140 were dissolved in $6 \mathrm{M} \mathrm{HCl}$ for two to five days on a hot plate at $110^{\circ} \mathrm{C}$.

142 All sample solutions were then separated into two aliquots for trace element and isotopic dilution (5$14310 \%)$ and Ce-Nd isotopic analyses (90-95\%). Ce and $\mathrm{Nd}$ were chemically separated following the 144 procedure reported in detail by Bonnand et al., 2019; modified from Tazoe et al., 2007 and Bellot et al., 1452015 and summarised here. REEs (including Ba) were first separated from the matrix using AG50WX8 resin. An additional step using AG1-X8 resin (200-400 mesh) was performed on the meteorites to remove $\mathrm{Fe}$. Then, $\mathrm{Ce}$ was separated from the trivalent REEs using an oxidation technique $\left(\mathrm{NaBrO}_{3}\right)$ on Ln-Spec resin, and purified in a final step using AG50W-X8 resin to remove any residual Ba. The remaining REE fraction was processed using Ln-Spec resin (25-50 mesh) and Nd was collected in 0.25 $\mathrm{M} \mathrm{HCl}$. Total procedural blanks for Ce and Nd were $0.4 \pm 1.7 \mathrm{ng}(2 \mathrm{sd}, n=12)$ and $0.02 \pm 0.05 \mathrm{ng}(2 \mathrm{sd}$, $n=7$ ), respectively, and were always negligible relative to the quantities collected from the samples.

We determined trace element abundances for all samples except NWA 8007, NWA 10854, and Adrar Bous by inductively coupled plasma mass spectrometry (ICP-MS) using the Agilent 7500 quadrupole instrument in normal mode (no collision cell) at LMV. These 3 meteorites were analysed using a Thermo iCAP quadrupole ICP-MS in collision cell mode with He flux at UWO. Concentrations were calculated using an external calibration (CMS reference material standard, Inorganic Ventures). We analysed certified rock standard BHVO-2 (or BCR-2 at UWO) together with our samples to assess the accuracy

161 of our analytical protocol.

163 We performed Ce isotopic analyses in static mode with double Re filaments on a ThermoScientific ${ }^{\mathrm{TM}}$

164 Triton Plus TIMS at LMV. Ce isotopes were measured as $\mathrm{CeO}^{+}$oxides using the procedure described 
and a baseline measurement (deflected ion beams) of $60 \mathrm{~s}$. Matrix rotation of the amplifiers was not

167 active because the $10^{11}, 10^{12}$, and $10^{13} \Omega$ resistors were used simultaneously. All corrections (oxygen, 168 mass discrimination using ${ }^{136} \mathrm{Ce} /{ }^{142} \mathrm{Ce}=0.01688$, and tailing effect) were performed offline. All reported 169 uncertainties are 2 standard deviations. During the course of the study, the value of the tailing correction 170 was $\Delta \varepsilon \mathrm{Ce}=0.77 \pm 0.18(n=151)$. Repeated measurements of our $\mathrm{Ce}_{\mathrm{LMV}}$ synthetic reference material 171 gave ${ }^{138} \mathrm{Ce} /{ }^{142} \mathrm{Ce}=0.02257063 \pm 54(24 \mathrm{ppm} ; n=31) .{ }^{138} \mathrm{Ce} /{ }^{142} \mathrm{Ce}$ ratios measured for rock reference 172 standards BCR-2 and BHVO-2 were equal to $0.02256684 \pm 48(21 \mathrm{ppm} ; n=9)$ and $0.02256453 \pm 99$

173 (44 ppm; $n=7$ ), respectively (see Supplementary data 2 for details on the total reproducibility of 174 measurements). The mean ${ }^{134} \mathrm{Ba}^{16} \mathrm{O}$ signal was $0.000003 \pm 0.000010 \mathrm{~V}(n=139)$, and the maximum 175 reached $1 \times 10^{-5} \mathrm{~V}$, which has no significant effect on the ${ }^{138} \mathrm{Ce} /{ }^{142} \mathrm{Ce}$ and ${ }^{136} \mathrm{Ce} /{ }^{142} \mathrm{Ce}$ ratios. Ce isotopic compositions of loess samples were measured on the same TIMS but using the two-line acquisition method of 360 cycles (Bellot et al., 2015).

178

179 We performed Nd isotopic analyses in static mode with double Re filaments using a ThermoScientific ${ }^{\mathrm{TM}}$ 180 Triton TIMS at LMV. A typical run comprised 18 blocks of 10 cycles, allowing a full rotation of the 181 amplifier system. Mass discrimination was corrected using ${ }^{146} \mathrm{Nd} /{ }^{144} \mathrm{Nd}=0.7219$. Repeated 182 measurements of the JNdi-1 standard and the two rock reference standards BCR-2 and BHVO-2 gave $183{ }^{143} \mathrm{Nd} /{ }^{144} \mathrm{Nd}=0.512099 \pm 4(7 \mathrm{ppm} ; n=16), 0.512623 \pm 8(17 \mathrm{ppm} ; n=3)$ and $0.512973 \pm 3(6 \mathrm{ppm} ; n$ $184=3$ ), respectively. The Sm contribution measured at mass 147 was negligible in all analyses.

\section{Results}

189 Measured Ce and Nd isotopic compositions are reported in Table 1 and 2, and details for individual runs 190 (number of cycles, mean intensity, tailing value) are given in Supplementary data 2. 
194 Chondrites define a small range of ${ }^{138} \mathrm{Ce} /{ }^{142} \mathrm{Ce}$ ratios between 0.02256522 and 0.02256633 , excluding

195 the two EL6 samples (Yilmia and Pillistfer) that show lower values (0.02256251 and 0.02256272,

196 respectively). Enstatite, ordinary, and carbonaceous chondrites have indistinguishable average values

197 within errors (Fig. 1A). The two EL6 samples plot on the $4.568 \mathrm{Ga}$ isochron in the ${ }^{138} \mathrm{Ce} /{ }^{142} \mathrm{Ce}$ vs. La/Ce

198 diagram (Fig. 1B) suggesting that their La/Ce ratios were modified early in the history of the Solar 199 System, in agreement with previous conclusions (Barrat et al., 2014; Boyet et al., 2018). Consequently, 200 we define the Ce isotopic composition of CHUR as the mean value of the other nine (i.e., unmodified) 201 chondrite samples: ${ }^{138} \mathrm{Ce} /{ }^{142} \mathrm{Ce}$ CHUR $=0.02256577 \pm 66(29 \mathrm{ppm})$.

203 To compare our CHUR value with the most recent estimates of Bellot et al. (2015) and Willig and 204 Stracke (2019), we have normalised these previous data using a common reference material 205 $\left({ }^{138} \mathrm{Ce} /{ }^{142} \mathrm{Ce}_{\mathrm{CeLmv}} /{ }^{138} \mathrm{Ce} /{ }^{142} \mathrm{Ce}_{\mathrm{CeAmES}}=0.02257053 / 0.02257426\right.$, Bonnand et al., 2019). The normalised CHUR value of Willig and Stracke $(2019)$ is thus ${ }^{138} \mathrm{Ce} /{ }^{142} \mathrm{Ce}=0.02256644 \pm 53$ (using ${ }^{136} \mathrm{Ce} /{ }^{142} \mathrm{Ce}=$ 0.01688), consistent with our estimate within errors. In contrast, the normalised CHUR value of Bellot et al. (2015) is significantly distinct from our value (Fig 1A). Combining the normalised data of Willig and Stracke (2019) with our measurements to calculate a mean chondritic ${ }^{138} \mathrm{Ce} /{ }^{142} \mathrm{Ce}$ ratio increases the uncertainty from 29 to $39 \mathrm{ppm}$ because their chondrite measurements were systematically $30 \mathrm{ppm}$ more

211 radiogenic than ours. This deviation exists also for MORB and OIB data and it is highlighted when data 212 are reported in a ${ }^{143} \mathrm{Nd} /{ }^{144} \mathrm{Nd}$ vs. ${ }^{138} \mathrm{Ce} /{ }^{142} \mathrm{Ce}$ isotope diagram. Thus, to compare these different datasets, 213 we henceforth strictly use the epsilon notation (Fig. 1B). In the future, to achieve better interlaboratory 214 reliability, chondrites should be measured under similar analytical conditions (see Supplementary Fig. 215 S5). 
The $\mathrm{Ce}$ and $\mathrm{Nd}$ isotopic compositions of terrestrial samples measured in this study are reported in a $\varepsilon \mathrm{Nd}$ vs. $\varepsilon$ Ce diagram (Fig. 2) and compared with recent MORB and OIB data from the literature. MORB samples have the least radiogenic $\mathrm{Ce}$ ratios and the most radiogenic $\mathrm{Nd}$ ratios, with $\varepsilon \mathrm{Ce}$ and $\varepsilon \mathrm{Nd}$ values ranging from -1.19 to -0.71 and from 8.85 to 10.42 , respectively. Pacific MORBs have slightly lower $\mathrm{Ce}$ isotopic ratios than Indian ones. OIB samples define larger compositional ranges with $\varepsilon \mathrm{Ce}$ and $\varepsilon \mathrm{Nd}$ values ranging from -1.44 to 0.43 and from -2.49 to 10.42 , respectively. Enriched mantle (EM1 and EM2)-like OIBs (Heard, Gough, Kerguelen, Tristan Da Cunha, São Miguel, and Tahaa) have the highest Ce isotopic ratios. Samples from Iceland and two samples from Hawaii plot in the MORB field. Other OIBs, including those with HIMU affinity (Saint-Helena), have compositions intermediate between Iceland samples and those with EM affinities, forming a continuum between these two end-members. The seven samples from Ethiopia have subchondritic $\varepsilon$ Ce values and plot along the OIB trend. The entire range of MORB $\varepsilon$ Ce values is relatively large (1 unit) compared to OIBs (1.5 units) considering the dispersion of $\varepsilon N d$ values ( 3 units for MORBs and 12 units for OIBs).

Loess samples have $\varepsilon \mathrm{Ce}$ and $\varepsilon \mathrm{Nd}$ values ranging from 1.6 to 2.0 and from -13.52 to -9.73 , respectively, 234 with average values of $\varepsilon \mathrm{Ce}=1.8 \pm 0.3$ and $\varepsilon \mathrm{Nd}=-11.2 \pm 3.0$. Our samples represent a sub-sampling of 235 those analysed by Chauvel et al. (2014), who determined a mean $\varepsilon N d$ value of $-10.3 \pm 2.3$, consistent 236 with our results.

\section{Discussion}

Dickin (1987) was the first to present coupled Ce and Nd isotopic measurements of OIB samples and 242 define the Ce-Nd mantle array. Recently, Willig and Stracke (2019) published new high-precision 243 measurements of MORBs and OIBs and refined the $\varepsilon$ Ce- $\varepsilon N d$ correlation. We extended their results by 244 analysing 66 new mantle-derived samples. The regression line calculated from all samples presented in 245 Figure $2(n=134)$ gives the following equation for the mantle array: $\varepsilon N d=-7.3( \pm 0.5) \times \varepsilon C e+0.4( \pm$ 
0.3 ), using Isoplot ${ }^{\circledR}$ and considering errors of 0.25 for $\varepsilon \mathrm{Ce}$ and 0.10 for $\varepsilon N d$. In agreement with Willig

247 and Stracke (2019), the mantle array intercepts the chondritic composition. However, we will show in

248 the following section that a chondritic intercept for the mantle array does not prove that these mantle-

249 derived samples come from a source with a chondritic light REE (LREE) pattern.

A non-chondritic REE composition of the primitive mantle was initially proposed to explain the radiogenic $\varepsilon N d$ values measured in Eoarchean samples (e.g., Chase and Patchett, 1988). High-precision isotopic measurements of the short-lived ${ }^{146} \mathrm{Sm}^{142}{ }^{14} \mathrm{Nd}$ systematics in both terrestrial samples and chondrites have strongly revived the debate on the nature of the REE composition of the PM (Boyet and Carlson, 2005). Most ${ }^{142} \mathrm{Nd} /{ }^{144} \mathrm{Nd}$ variations measured in the different chondrite groups are now attributed to initial isotopic heterogeneities of nucleosynthetic origin within the solar nebula during planetary accretion (Bouvier and Boyet, 2016; Burkhardt et al., 2016; Carlson et al., 2007). However, in terms of non-radiogenic $\mathrm{Nd}$ isotope compositions, enstatite chondrites are the closest to the Earth and, on average, are depleted in ${ }^{142} \mathrm{Nd}$ by $10 \mathrm{ppm}$ relative to terrestrial samples (Boyet et al., 2018; Dauphas, 2017) with the exception of the EL3 sub-group. Carbonaceous chondrites may have been involved during the last stage of Earth's accretion, and, because they are depleted in ${ }^{142} \mathrm{Nd}$ by $32 \mathrm{ppm}$ relative to terrestrial samples, they may have further contributed to the difference between terrestrial and EC values (Boyet et al., 2018). None of the current meteorite groups available for analysis and mixing models satisfy the isotopic and elemental composition of the Earth, and call for unknown end-members or

267 fractionation processes. Thus, it is still possible that some of the observed difference between terrestrial 268 and chondritic ${ }^{142} \mathrm{Nd}$ abundances was produced by the decay of ${ }^{146} \mathrm{Sm}$ in a superchondritic $\mathrm{Sm} / \mathrm{Nd}$ reservoir.

271 To attempt to constrain the REE composition of the PM, we consider a $10 \mathrm{ppm}$ increase in radiogenic

$272{ }^{142} \mathrm{Nd}$ that corresponds to the difference between modern terrestrial samples and either EC values having 
273 a terrestrial mean ${ }^{142} \mathrm{Nd} /{ }^{144} \mathrm{Nd} 10 \mathrm{ppm}$ higher than that of the continental crust, or an Earth made with

$27490 \%$ of EL3 chondrites $+10 \%$ carbonaceous chondrites (Boyet et al., 2018). This excess ${ }^{142} \mathrm{Nd}$ would 275 have been produced in a high-Sm/Nd reservoir. Assuming this reservoir formed $4.568 \mathrm{Ga}$, this 276 corresponds to a $3.6 \%$ increase of the $\mathrm{BSE} \mathrm{Sm} / \mathrm{Nd}$ ratio relative to the chondritic value. Modelled $\mathrm{Sm} / \mathrm{Nd}$ 277 ratios in early-differentiated reservoirs have been discussed in a large number of publications (e.g. Boyet 278 and Carlson, 2005; Caro et al., 2008) and can goes up to 5\% higher if this early-differentiated reservoir 279 formed $4.5 \mathrm{Ga}$. Here we use the terms "early depleted reservoir" (EDR) and "early enriched reservoir" 280 (EER) as defined by Boyet and Carlson (2005): the EDR has a chondrite-normalised REE pattern that 281 is depleted in LREEs relative to heavy REEs and thus a superchondritic $\mathrm{Sm} / \mathrm{Nd}$ ratio, whereas the 282 complementary EER has a subchondritic Sm/Nd ratio. The EER may exist in the lower mantle (Boyet 283 and Carlson, 2005) or may correspond to embryonic crust lost by collisional erosion during Earth's 284 accretion (O’Neill and Palme, 2008).

286 We calculate the REE composition of the EDR by the method developed by Jackson and Jellinek (2013), 287 which is based on three different isotopic systematics $\left({ }^{146} \mathrm{Sm}-{ }^{142} \mathrm{Nd},{ }^{147} \mathrm{Sm}-{ }^{143} \mathrm{Nd}\right.$, and $\left.{ }^{176} \mathrm{Lu}-{ }^{176} \mathrm{Hf}\right)$ and 288 invariant elemental ratios (e.g., Sm/Hf). CHUR REE elemental ratios needed for this calculation were 289 obtained from a large and recent database of ordinary, enstatite, and carbonaceous chondrites (Barrat et al., 2012, 2014; Boyet et al., 2018; Braukmüller et al., 2018; Dauphas and Pourmand, 2015; Pourmand 291 et al., 2012). We selected the least thermally metamorphosed fall samples (types $1-4, n=42$ ), and 292 outliers (Orgueil and Kelly) were removed. The mean La/Ce ratio thus calculated for CHUR is $0.387 \pm$ $2930.022(n=39)$, similar to the value we obtained from our smaller sample set $\left(\mathrm{La} / \mathrm{Ce} \mathrm{CHUR}_{\mathrm{R}}=0.390 \pm\right.$ 294 0.022). The CHUR Sm/Nd ratio determined from the same database of chondrite samples is $0.324 \pm$ 295 0.014, consistent with the value proposed by Bouvier et al. (2008). Lastly, we used the Lu/Hf ratio of 296 CHUR (0.236) calculated from the average ${ }^{176} \mathrm{Lu} /{ }^{177} \mathrm{Hf}$ value determined by Bouvier et al. (2008).

298 The calculated REE pattern for an EDR is presented in Figure 3. For a 3.6\% increase of the $\mathrm{Sm} / \mathrm{Nd}$ ratio 299 of the BSE, the modelled EDR has $\varepsilon \mathrm{Ce}=-0.4$ and $\varepsilon \mathrm{Nd}=4.1$. This reservoir plots very close to the 300 mantle array in the $\varepsilon \mathrm{Nd}$ vs. $\varepsilon$ Ce diagram, and shows Ce-Nd isotopic compositions similar to those 
measured in several OIBs (Fig. 4). A large-scale silicate differentiation event early in the Solar System's evolution does not produce any offset in the Ce-Nd isotopic composition of the EDR relative to the mantle array. Thus, defining the Ce-Nd mantle array does not resolve the long-standing debate over the chondritic vs. EDR-like REE composition of the PM.

\subsection{Crustal extraction mass-balance calculations}

Mantle melting and subsequent extraction of the crust has contributed to the depletion of the mantle in incompatible elements. Crustal growth models are widely discussed and several authors have proposed rapid continental growth early in Earth's history despite the scarce geological record of the Earth's first 311 billion years (Belousova et al., 2010; Dhuime et al., 2012). Geochemical signatures in mantle-derived samples linked to this process are particularly difficult to decipher because surface material is continuously reintegrated into the mantle via subduction. In this section, to investigate the production of the various mantle reservoirs, we attempt to recreate the Ce-Nd mantle array via mass-balance mixing calculations between the depleted MORB mantle (DMM) and continental crust (CC). We first simplify our approach by assuming that the $\mathrm{CC}$ was extracted from the $\mathrm{PM}$ in a single differentiation step (i.e., $\mathrm{DMM}+\mathrm{CC}=\mathrm{BSE})$. Since we have not resolved the chondritic vs. EDR-like composition of the PM, we explore both bulk compositions and compare their modelled Ce-Nd mixing curves to the mantle array. Distinct scenarios proposed that oceanic crust formation was the dominant process of mantle depletion with continents formed later by reworking in subduction zones (e.g., Jones et al., 2019).

321 Furthermore, isotopic studies of rocks from the Nuvvuaggituq Supracrustal Belt and the neighbouring

322 Hudson Bay terrane show that the Archean felsic crust formed by reworking of Hadean mafic crust 323 (O'Neil et al., 2019; O'Neil and Carlson, 2017). From these observations, we choose to calculate the 324 Ce-Nd isotopic composition of such an enriched reservoir and compare it to the global dataset to evaluate the effect of primitive mafic crustal extraction on the mantle. 
The DMM end-member isotopic composition is commonly calculated from MORB samples. Our

330 measurements and literature data are plotted in the $\varepsilon N d$ vs. $\varepsilon$ Ce diagram (Fig. 2). The average of 48

331 MORB measurements gives $\varepsilon \mathrm{Ce}_{\mathrm{DMM}}=-1.1 \pm 0.6$ and $\varepsilon \mathrm{Nd}_{\mathrm{DMM}}=9.7 \pm 2.3$. This mean $\mathrm{Nd}$ isotopic

332 composition is consistent with previously proposed values of 9.2 and 9.8 based on a more complete 333 dataset (Salters and Stracke, 2004, and Workman and Hart, 2005, respectively). Restricting the MORB 334 samples to those that do not show the Dupal anomaly (i.e., North Atlantic and Pacific MORBs) gives 335 an identical result $(\varepsilon \mathrm{Ce}=-1.2 \pm 0.6, n=33)$.

\section{Continental Crust}

338 The CC is a low-mass reservoir containing $20-70 \%$ of the PM's incompatible element budget. The 339 difficulty in constraining the $\mathrm{CC}$ composition stems from its nature. With a mean age of $1.8-2.4 \mathrm{Ga}$ 340 (Chauvel et al., 2014; Taylor and McLennan, 1995) and an average thickness of about $40 \mathrm{~km}$, it is much 341 older and thicker than the present-day oceanic crust. The major- and trace-element compositions of the 342 upper, middle, and lower crust are based on numerous rock samples from which global compositions 343 were obtained (Rudnick and Gao, 2003, and references therein), though the isotopic composition of the 344 bulk CC is largely under-constrained; very few data are available for $\mathrm{Ce}$, and $\varepsilon \mathrm{Nd}$ values generally vary 345 between -21 and -10 . Based on loess measurements, Chauvel et al. (2014) proposed a model age of 1.8 346 Ga for the UCC and a $\varepsilon N d$ value of -10 . On the other hand, Goldstein and Jacobsen (1988) considered suspended materials in rivers $\left(\varepsilon N d=-11, \mathrm{~T}_{\mathrm{DM}}=1.6 \mathrm{Ga}\right)$ but corrected their mean value for the 348 preferential erosion of young terranes $(\varepsilon N d=-17$ recalculated at $2.1 \mathrm{Ga})$. Similarly, Hawkesworth et al.

349 (2017) discussed the erosional bias based on the proportions of young and old source rocks and proposed 350 a bulk CC $\varepsilon N d$ value of -12 . Other studies consider that the upper and bulk crusts have distinct isotope 351 signature; Allègre and Lewin (1989) calculated a $\varepsilon N d$ value of -21 from DMM-bulk CC mass-balance 352 equations, whereas Jacobsen and Wasserburg (1980) obtained a slightly higher value with a similar 353 approach $(\varepsilon \mathrm{Nd}=-14)$.

355 To date, $\mathrm{CC}$ rocks analysed for $\mathrm{Ce}$ and $\mathrm{Nd}$ isotopes are mainly $\sim 2 \mathrm{Ga}$ granites and gneisses (see 356 Supplementary Fig. S6 for details). Combining all published Ce-Nd measurements gives average values 
of $\varepsilon \mathrm{Ce}=2.8$ and $\varepsilon \mathrm{Nd}=-19$ (Fig. 4). This is slightly different from the sole published estimate for the

$358 \mathrm{CC}(\varepsilon \mathrm{Ce}=1.3$ and $\varepsilon \mathrm{Nd}=-14$; Tanaka et al., 1987), which was calculated by regression from five crustal 359 rock measurements $(\varepsilon \mathrm{Ce}=-0.112 \times \varepsilon \mathrm{Nd})$ anchored to the mean $\varepsilon \mathrm{Nd}$ value of aeolian sediments and 360 particulates in rivers $(\varepsilon \mathrm{Nd}=-11.4$; Goldstein et al., 1984). Our loess average is $\varepsilon \mathrm{Ce}=1.8$ and $\varepsilon \mathrm{Nd}=-$ 361 11.2, relatively close to Tanaka et al.'s (1987) value.

\section{Mafic crust}

364 Results obtained on the ${ }^{146} \mathrm{Sm}^{142} \mathrm{Nd}$ short-lived systematics suggest that the oldest mafic crust preserved at the Earth's surface is the $\sim 4.3$ Ga Nuvvuagittuq Supracrustal Belt in northern Quebec (O'Neil et al., 2008). Even if this age is debated, the neighbouring Hudson Bay terrane shows that the Archean felsic crust formed by reworking of an Hadean mafic crust (O’Neil et al., 2019; O’Neil and Carlson, 2017). We chose sample PC-162 $(\mathrm{La} / \mathrm{Ce}=0.49$ and $\mathrm{Sm} / \mathrm{Nd}=0.27)$ as representative of the Archean mafic crust to model its $\mathrm{Ce}$ and $\mathrm{Nd}$ isotopic compositions. This and other samples from the enriched low-Ti group (O’Neil et al., 2011) are enriched in LREEs by 10 to 80 times the chondritic reference, whereas rocks from the depleted low-Ti and high-Ti units show lower LREE enrichments ( $<20$ times). Furthermore, PC-162 is one of the most REE-depleted samples among those of the enriched low-Ti group that do not show any evidence of metamorphic disturbance (O'Neil et al., 2012), and thus its REE contents correspond to a reasonable crustal extraction rate: that is, more enriched compositions reflect increased depletion of the mantle during extraction of the crust. The Ce-Nd isotopic compositions of the modelled mafic end-member are reported in Figure 4; they are identical $(\varepsilon \mathrm{Ce}=3.8$ and $\varepsilon \mathrm{Nd}=-17.3)$ for a crust formed at $4.3 \mathrm{Ga}$, irrespective of the PM considered (CHUR or EDR). The EER calculated by Carlson 378 and Boyet (2008) has similar $\mathrm{La} / \mathrm{Ce}$ and $\mathrm{Sm} / \mathrm{Nd}$ ratios of 0.47 and 0.28 , respectively, producing present379 day isotopic compositions of $\varepsilon \mathrm{Ce}=3$ and $\varepsilon \mathrm{Nd}=-13.5$ if this reservoir formed $4.3 \mathrm{Ga}$. Both these models 380 plot to the right of the mantle array (Fig. 4). 
Our mass-balance models consider DMM-CC complementarity for chondritic and early-depleted PM compositions. We aim to determine the $\varepsilon$ Ce value of the $\mathrm{CC}$ using four-successive calculation steps (Supplementary material). 1) We calculate the mass fraction of $\mathrm{Nd}$ in the $\mathrm{CC}$ relative to the total amount in the crust and DMM (the sialic index; e.g., Allègre and Lewin, 1989) based on the DMM, CHUR/EDR (Table 3), and CC $\varepsilon N d$ values. As the range of published CC isotopic values is large, we do not set a precise $\varepsilon N d$ value in the mass-balance model, but consider all possibilities between $\varepsilon N d=-10$ and -21 .

2) We calculate the mass fraction of CC using the Nd contents of the BSE (as determined in section 5.2 with REE patterns anchored to a Lu content of 68 ppb; McDonough and Sun, 1995) and CC (Rudnick and Gao, 2003). The Ce/Nd ratio is set to 1.28 for a chondritic BSE and to 1.22 for the EDR model (Table 3). Importantly, the Lu value chosen to anchor the REE pattern of the BSE has no consequence on the final $\varepsilon$ Ce value. 3) The Ce sialic index is calculated using the Ce contents of the BSE (see step 2) and CC (Rudnick and Gao, 2003). 4) The $\varepsilon$ Ce value of the CC is calculated from the Ce sialic index and the $\varepsilon C e$ values of the DMM and CHUR/EDR (Table 3): $\varepsilon \mathrm{Ce}_{\mathrm{CC}}$ varies from 0.2 to 1 in the chondritic case and from 0.4 to 1.2 in the EDR case. All CCs are represented as orange or green lines at the lower end of the mixing curves in Figure 4 (chondritic or EDR model, respectively) and all calculated DMM-CC mixing hyperbolas are plotted in the form of a coloured field. Their curvature is a function of the $\mathrm{Ce} / \mathrm{Nd}$ ratios of both end-members.

In the upper left of the $\varepsilon \mathrm{Nd}$ vs. $\varepsilon$ Ce diagram, the DMM-CC mixing hyperbolas overlap and pass through

403 both the CHUR and EDR compositions. However, they do not fully overlap the data points defining the 404 mantle array. The Ce-Nd isotopic compositions calculated for the $\mathrm{CC}$ are always less radiogenic in 405 cerium than the mean values estimated from measurements, which might question the relevance of the 406 published data used to estimate the isotopic composition of the bulk CC. Most of the samples are upper crust (e.g., loess) samples. If the observed difference reflects heterogeneities within the crustal reservoir,

408 the lower and middle crust should be characterised by negative $\varepsilon$ Ce values to adjust the mass balance budget within the continental crust (Willig and Stracke, 2019). However, Vervoort et al. (2000) suggested that lower crustal xenoliths have $\varepsilon \mathrm{Hf}-\varepsilon \mathrm{Nd}$ values close to the mantle array. 
412 The mass fraction of depleted mantle relative to the whole mantle can be calculated in the case of the

413 mass balance calculations for the entire range of $\varepsilon \mathrm{Nd}_{\mathrm{CC}}$ considered. It varies from 14 to $33 \%$ and from 41428 to $64 \%( \pm 20 \%)$ for the CHUR and EDR bulk compositions, respectively (Fig. 5). As mentioned in 415 section 5.3.1, a more depleted initial composition implies that a larger volume of the mantle was depleted 416 by crustal extraction (Boyet and Carlson, 2006). For comparison, Allègre and Lewin (1989) calculated 417 the mass fraction of depleted mantle to be comprised between 32 and $40 \%$ using a chondritic BSE.

The mixing curve joining the DMM and a 4.3 Ga early mafic crust is also reported in Figure 4. The $\mathrm{Ce} / \mathrm{Nd}$ ratio of this mafic crust is 1.9 , only slightly different from the mean value of 2.15 determined for the CC by Rudnick and Gao (2003). Thus, the DMM-mafic crust mixing hyperbola has a curvature close to that of the DMM-CC mixing curve. Again, such a mixing scenario seems unlikely to reproduce the mantle array.

5.3.3. What parameters can bring the DMM-CC mixing model closer to the mantle array?

To superimpose the DMM-CC mixing curve on the mantle array, Willig and Stracke (2019) proposed using a more depleted isotopic composition for the DMM end-member (see their Figure 5). However, for a likely $\mathrm{CC}$ Nd isotopic composition, such a DMM-CC hyperbola requires DMM Ce-Nd isotopic ratios very different from those measured in MORB samples. For example, to fully reproduce the mantle array, the $\varepsilon \mathrm{Ce}$ and $\varepsilon \mathrm{Nd}$ values of the DMM should be approximately -10 and +40 , respectively, if we set the $\varepsilon N d$ value of the bulk CC to -17 (in the case of a chondritic BSE). Such compositions have never been measured in MORBs or peridotites.

Several authors have proposed loess samples to be a good approximation of the upper crust because these clastic rocks sample large surface areas and have relatively uniform $\mathrm{Nd}$ and $\mathrm{Hf}$ isotopic compositions (e.g., Chauvel et al., 2014). Because the lower crust appears to have Hf-Nd isotopic ratios 438 similar to those of the upper crust (Vervoort et al., 2000), we also calculated the $\varepsilon$ Ce- $\varepsilon N d$ mixing hyperbola between the DMM end-member and a loess-like component. Its curvature is a function of the 
$\mathrm{Ce} / \mathrm{Nd}$ ratios of both end-members. The mean $\mathrm{Ce} / \mathrm{Nd}$ value calculated from our loess samples $(2.38 \pm$

4410.30 ) is similar within errors to the value of 2.33 determined for the upper crust by Rudnick and Gao

442 (2003) and to that of the global subducting sediment reservoir that represents the bulk composition of 443 trench sediments (Plank, 2014). However, this result is more than twice the Ce/Nd ratios of 1.08 and 4440.95 determined for the DMM by Salters and Stracke (2004) and Workman and Hart (2005), 445 respectively. Consequently, considering the Ce-Nd isotopic composition of loess as representative of 446 the CC moves the DMM-CC mixing curve further from the mantle array (Fig. 4).

The model age of loesses is $1.8 \mathrm{Ga}$ (Chauvel et al., 2014), which is not widely agreed to be the mean age of the crust. An older equivalent $(2.2 \mathrm{Ga})$ of these samples would have a less radiogenic $\mathrm{Ce}-\mathrm{Nd}$ isotopic composition that still plots on the mantle array. Superimposing the DMM-loess mixing curve on the mantle array (i.e., to linearise the DMM-loess hyperbola) requires increasing the DMM Ce/ $\mathrm{Nd}$ ratio towards a value identical to that of loesses. Unlike the $\mathrm{CC}$ reservoir, which has been calculated from a large number of measurements, the DMM remains a model based on a series of assumptions, such that its REE pattern can be questioned. Such a reservoir is represented in MORB Ce and Nd isotopic compositions as a strong long-term depleted $\mathrm{REE}$ element pattern, and a consistent $\mathrm{Ce} / \mathrm{Nd}_{\mathrm{DMM}}$ ratio requires the DMM to have a positive Ce elemental anomaly. Cerium anomaly generally reflects a specific behaviour of $\mathrm{Ce}^{4+}$ relative to $\mathrm{REE}^{3+}$. However, such a Ce anomaly has never been measured in 458 MORBs.

The DMM-loess mixing curve coincides with the repartition of Island Arc Basalts (IABs) from the 461 Lesser Antilles and the Mariana Islands (Bellot et al., 2015, 2018). The isotopic compositions of OIBs and IABs differ from those of MORBs due to the introduction of crustal material into their sources. 463 Although the isotopic compositions of arc lavas can be modified by post-melting reactions such as 464 assimilation-fractional crystallisation processes (AFC), this is not the case for the Marianas and Lesser 465 Antilles (e.g., Labanieh et al., 2010), and their Ce-Nd isotopic compositions are well explained by the 466 incorporation of sediments into the mantle wedge (Bellot et al., 2015, 2018). We expect a larger 467 incorporation of sediments in arc lavas relative to hotspot lavas since REEs are enriched in slab 
dehydration fluids, whereas sediments are recycled with oceanic crust into the OIB source and their signatures are consequently diluted. Indeed, OIBs and IABs are clearly distinct in the $\varepsilon \mathrm{Ce}-\varepsilon \mathrm{Nd}$ diagram 470 (Fig. 4).

The EM1, EM2, and HIMU mantle end-members have been defined from the most extreme isotopic compositions measured in OIBs (Zindler and Hart, 1986) and are classically interpreted as representing the recycling of surface materials into the deep mantle. Chauvel et al. (2008) modelled the Hf and Nd isotopic compositions of basaltic crust and sediments recycled at different times during Earth's history and showed that the Hf-Nd mantle array required the incorporation of surface material older than $2 \mathrm{Ga}$ into the OIB source. Here we apply the evolution model to the Ce-Nd systematics (see Supplementary Fig. S7): 1) the isotopic composition of recycled sediments and recycled oceanic crust (ROC) calculated back in time is assumed to be on the evolution line built between their present-day isotopic composition and the CHUR value at $4.568 \mathrm{Ga}$; 2) the actual isotopic compositions of these two reservoirs are then calculated considering the parent/daughter ratios in their source reservoirs. To this end, we consider the mean ${ }^{143} \mathrm{Nd} /{ }^{144} \mathrm{Nd},{ }^{138} \mathrm{Ce} /{ }^{142} \mathrm{Ce},{ }^{147} \mathrm{Sm} /{ }^{144} \mathrm{Nd}$, and ${ }^{138} \mathrm{La} /{ }^{142} \mathrm{Ce}$ ratios measured in oceanic sediments in front of the Mariana trench (Sites 801 and 802, ODP Leg 129; Bellot et al., 2018) and near the Lesser Antilles arc (DSDP site 144; Bellot et al., 2015) together with those of the MORB samples plotted in Figure 2. Modern oceanic sediments are characterised by negative elemental cerium anomalies, reflecting an oxidised environment. Before the GOE, dated around $2.4 \mathrm{Ga}$ (see Holland, 2002), all REEs 490 in sediments were necessarily trivalent under the anoxic conditions. Thus, we removed the elemental 491 cerium anomaly from all oceanic sediments older than $2.4 \mathrm{Ga}$.

493 Our calculations produce important results. First, the ROC follows a positive slope in the $\varepsilon$ Ce- $\varepsilon N d$ 494 diagram, whereas the mantle array defines a negative slope (Fig. 6, see Supplementary Fig. S7 for further 
toward slightly less radiogenic Ce isotopic ratios than MORBs. Second, as previously shown by Chauvel

497 et al. (2008), the mantle array can be reproduced by mixing either a DMM-like or a FOZO-like 498 component (FOZO is assumed to have $\varepsilon \mathrm{Ce}=-0.6$ and $\varepsilon \mathrm{Nd}=6.24$; see Boyet et al., 2019) and recycled surface material (ROC and sediments have the same recycling ages). On the sole basis of $\mathrm{Ce}$ and $\mathrm{Nd}$ isotopes, it is still unclear whether the different plume sources contain surface material recycled at various time or pre-GOE material in various proportions (the two propositions being not mutually exclusive). Also, the intersections of the recycled crust-sediment mixing curves and the mantle array indicate the proportion of sediments in the recycled material $\left(\mathrm{m}_{\text {sediments }} /\left(\mathrm{m}_{\text {sediments }}+\mathrm{m}_{\text {oceanic crust }}\right)\right)$ to be 504 between 6 and 12\%; this proportion decreases for younger recycled components. This last result must be considered in parallel with the decreasing rate of crustal destruction until the present value of 3.2$5.5 \mathrm{~km}^{3} \mathrm{yr}^{-1}$ (Dhuime et al., 2018, and references therein).

508 Sediments formed before and after the GOE evolved to distinct Ce isotopic compositions. For a similar 509 proportion of sediments in the recycled component (i.e., $10 \%$ sediment and $90 \%$ oceanic crust), the $\varepsilon \mathrm{Ce}$ 510 value of a $2.5 \mathrm{Ga}$ recycled component is inferior by $0.3 \varepsilon$-units when we remove the Ce anomaly. More 511 importantly, in our model, only the recycling of pre-GOE sediments can explain the most enriched isotopic compositions measured in OIBs. Corresponding samples are classified either as EM1 (samples from Tristan Da Cunha, Gough, Heard, and Kerguelen Islands) or EM2 (Tahaa Island in the Society 514 archipelago). The Ce-Nd isotopic composition of Gough Island lavas was explained by the incorporation 515 of subcontinental lithospheric material at shallow depths into the mantle (Boyet et al., 2019). The lack 516 of correlation between the cerium anomalies and the Ce isotope compositions measured in Gough Island 517 lavas proves that ancient sediments carrier of negative element cerium anomaly were not incorporated 518 in the Gough mantle source. Moreover, mass-independent S isotopic fractionations measured in olivinehosted sulphides from other EM1 (e.g., Pitcairn) lavas similarly suggest the recycling of surface materials that existed in a reduced atmosphere before the GOE (Cabral et al., 2013; Delavault et al., 521 2016). 


\section{Conclusions}

526 We measured the Ce isotopic compositions of 51 OIBs, 1 intraplate continental volcanism occurrence, 5277 MORBs, 6 loess samples, and 11 chondrites, enhancing the terrestrial and extra-terrestrial Ce isotopic 528 database. We define the ${ }^{138} \mathrm{Ce} /{ }^{142} \mathrm{Ce}$ CHUR reference to be $0.02256577 \pm 66$. OIB and MORB samples 529 define the mantle array as $\varepsilon \mathrm{Nd}=-7.3( \pm 0.5) \times \varepsilon \mathrm{Ce}+0.4( \pm 0.3)$. The mantle array passes through the 530 CHUR value and is not significantly different from a modelled early-depleted reservoir. We conclude 531 that combining $\mathrm{Ce}$ and $\mathrm{Nd}$ isotopic measurements in mantle-derived samples does not further constrain 532 the composition of the PM.

534 Mixing models between the DMM and CC end members, both estimated from sample measurements (upper, or early mafic crusts), cannot reproduce the Ce-Nd mantle array but better fit IAB data. The mantle array is better reproduced by considering bulk CCs consistent with a mass-balance budget of the BSE (Ce isotopic compositions calculated for a range of accepted Nd). But the mixing hyperbolas do not perfectly overlap the OIB samples with subchondritic Ce isotopic composition; and the calculated $\varepsilon$ Ce for the bulk crust are significantly different from all crustal rocks measured so far. In all these models, linearising the mixing curves requires unrealistic Ce-Nd isotopic compositions and/or Ce/ $\mathrm{Nd}$ ratios never measured in rock samples. Alternatively, the recycling of sediments and oceanic crust into hotspot sources, and their mixing with DMM- or FOZO-like material may explain the Ce-Nd mantle array. Our results further show that Ce-Nd isotopic compositions measured in the most enriched EM-

544 like lavas can be reproduced by the incorporation in their source of recycled oceanic sediments that do 545 not have any elemental $\mathrm{Ce}$ anomaly. Because $\mathrm{Ce}$ is a redox-sensitive trace element that can be used to 546 trace the oxygenation of atmosphere (GOE at $2.4 \mathrm{Ga}$ ), our results suggest that some OIBs sample very 547 deep mantle reservoirs that may preserve pre-GOE recycled surface materials, in agreement with 548 observed S isotopic fractions in EM1 lavas. Constraining the long-term history of recycled surface material in the mantle is essential to understand the isotope signature of mantle-derived samples. The

550 La-Ce isotope systematics offers a unique opportunity to detect changes on the chemical composition 551 of oceanic sediments through time. 


\section{Acknowledgments}

554

555 We thank Raphael Pik, Manuel Moreira, Dan McKenzie, Pierre Schiano, Bertrand Moine, Ivan 556 Vlastelic, Jane Barling, and Catherine Chauvel for providing OIB and loess samples. We also 557 acknowledge Anthony Irving (University of Washington - Oudiyat Sbaa), the Western Australian 558 Museum (Yilmia - off WAM 13197), the National History Museum (University of Tartu - Pillistfer 559 TUG 552-2), the Smithsonian Institution National Museum of Natural History (Allende - 45NM3529), 560 and the Muséum d'Histoire Naturelle de Paris (Agen - 1479 ; Saint-Severin - 2397 PE2) for providing 561 chondrites. We thank the Geological Survey of Japan for providing the isotopic standard JNdi-1. The 562 reference material $\mathrm{Ce}_{\mathrm{LMV}}$ is available upon request. Detailed reviews by Richard W. Carlson and an 563 anonymous reviewer are much appreciated as are the editorial handling by Rajdeep Dasgupta. We also 564 thank K.R. Ludwig for the use of his program Isoplot ${ }^{\circledR}$. This project has received funding from the 565 European Research Council (ERC) under the European Union's Horizon 2020 research and innovation 566 program (Grant Agreement No. 682778 - ISOREE). AB thanks support from the Canada Foundation

567 for Innovation and NSERC Discovery Grant and CRC programs. This is Laboratory of Excellence 568 ClerVolc contribution no. XX.

\section{Appendix A. Supplementary material}

573 Supplementary material related to this article can be found online at XX.

574 Supplementary data 1: Major and trace element contents measured by quadrupole ICP-MS.

575 Supplementary data 2: Ce and Nd isotopic ratios of standard and rock samples and supplementary 576 information. 
Supplementary material: 1) Sample descriptions from trace element diagrams and Ce anomalies; 2)

${ }^{138} \mathrm{Ce} /{ }^{142} \mathrm{Ce}$ ratios from literature and example of normalisation with MORB; 3$){ }^{138} \mathrm{Ce} /{ }^{142} \mathrm{Ce}$ ratios of crustal samples from literature; 4) mass-balance calculations; and 5) recycling models.

\section{References}

Allègre, C.J., Lewin, É., 1989. Chemical structure and history of the Earth: evidence from global nonlinear inversion of isotopic data in a three-box model. Earth Planet. Sci. Lett. 96, 61-88. https://doi.org/10.1016/0012-821X(89)90124-6

Allègre, C.J., Manhès, G., Lewin, É., 2001. Chemical composition of the Earth and the volatility control on planetary genetics. Earth Planet. Sci. Lett. 185, 49-69. https://doi.org/10.1016/S0012$821 X(00) 00359-9$

Barrat, J.A., Zanda, B., Jambon, A., Bollinger, C., 2014. The lithophile trace elements in enstatite chondrites. Geochim. Cosmochim. Acta 128, 71-94. https://doi.org/10.1016/j.gca.2013.11.042

Barrat, J.-A., Zanda, B., Moynier, F., Bollinger, C., Liorzou, C., Bayon, G., 2012. Geochemistry of CI chondrites: Major and trace elements, and $\mathrm{Cu}$ and $\mathrm{Zn}$ isotopes. Geochim. Cosmochim. Acta 83, 79-92. https://doi.org/10.1016/j.gca.2011.12.011

Begemann, F., Ludwig, K.R., Lugmair, G.W., Min, K., Nyquist, L.E., Patchett, P.J., Renne, P.R., Shih, C.-Y., Villa, I.M., Walker, R.J., 2001. Call for an improved set of decay constants for geochronological use. Geochim. Cosmochim. Acta 65, 111-121. https://doi.org/10.1016/S00167037(00)00512-3

Bellot, N., Boyet, M., Doucelance, R., Bonnand, P., Savov, I.P., Plank, T., Elliott, T., 2018. Origin of negative cerium anomalies in subduction-related volcanic samples: Constraints from $\mathrm{Ce}$ and $\mathrm{Nd}$ isotopes. Chem. Geol. 500, 46-63. https://doi.org/10.1016/j.chemgeo.2018.09.006

Bellot, N., Boyet, M., Doucelance, R., Pin, C., Chauvel, C., Auclair, D., 2015. Ce isotope systematics of island arc lavas from the Lesser Antilles. Geochim. Cosmochim. Acta 168, 261-279. 
Belousova, E.A., Kostitsyn, Y.A., Griffin, W.L., Begg, G.C., O’Reilly, S.Y., Pearson, N.J., 2010. The growth of the continental crust: Constraints from zircon Hf-isotope data. Lithos 119, 457-466. https://doi.org/10.1016/j.lithos.2010.07.024

Blichert-Toft, J., Frey, F.A., Albarède, F., 1999. Hf Isotope Evidence for Pelagic Sediments in the Source of Hawaiian Basalts. Science 285, 879. https://doi.org/10.1126/science.285.5429.879

Bonnand, P., Israel, C., Boyet, M., Doucelance, R., Auclair, D., 2019. Radiogenic and stable Ce isotope measurements by thermal ionisation mass spectrometry. J. Anal. At. Spectrom. https://doi.org/10.1039/C8JA00362A

Bouhifd, M.A., Boyet, M., Cartier, C., Hammouda, T., Bolfan-Casanova, N., Devidal, J.L., Andrault, D., 2015. Superchondritic Sm/Nd ratio of the Earth: Impact of Earth's core formation. Earth Planet. Sci. Lett. 413, 158-166. https://doi.org/10.1016/j.eps1.2014.12.054

Bouvier, A., Boyet, M., 2016. Primitive Solar System materials and Earth share a common initial 142Nd abundance. Nature 537, 399-402. https://doi.org/10.1038/nature19351

Bouvier, A., Vervoort, J.D., Patchett, P.J., 2008. The Lu-Hf and Sm-Nd isotopic composition of CHUR: Constraints from unequilibrated chondrites and implications for the bulk composition of terrestrial planets. Earth Planet. Sci. Lett. 273, 48-57. https://doi.org/10.1016/j.eps1.2008.06.010

Boyet, M., Bouvier, A., Frossard, P., Hammouda, T., Garçon, M., Gannoun, A., 2018. Enstatite chondrites EL3 as building blocks for the Earth: The debate over the $146 \mathrm{Sm}-142 \mathrm{Nd}$ systematics. Earth Planet. Sci. Lett. 488, 68-78. https://doi.org/10.1016/j.eps1.2018.02.004

Boyet, M., Carlson, R.W., 2006. A new geochemical model for the Earth's mantle inferred from 146Sm-142Nd systematics. Earth Planet. Sci. Lett. 250, 254-268. https://doi.org/10.1016/j.eps1.2006.07.046

Boyet, M., Carlson, R.W., 2005. 142Nd evidence for early (> $4.53 \mathrm{Ga}$ ) global differentiation of the silicate Earth. Science 309, 576-581. https://doi.org/10.1126/science.1113634

Boyet, M., Doucelance, R., Israel, C., Bonnand, P., Auclair, D., Suchorski, K., Bosq, C., 2019. New constraints on the origin of the EM-1 component revealed by the measurement of the La-Ce isotope systematics in Gough Island lavas. Geochem. Geophys. Geosystems 20. https://doi.org/10.1029/2019GC008228 
633 Braukmüller, N., Wombacher, F., Hezel, D.C., Escoube, R., Münker, C., 2018. The chemical

634 composition of carbonaceous chondrites: Implications for volatile element depletion,

635 complementarity and alteration. Geochim. Cosmochim. Acta 239, 17-48.

$636 \quad$ https://doi.org/10.1016/j.gca.2018.07.023

637 Burkhardt, C., Borg, L.E., Brennecka, G.A., Shollenberger, Q.R., Dauphas, N., Kleine, T., 2016. A

638 nucleosynthetic origin for the Earth's anomalous 142Nd composition. Nature 537, 394-398.

639 https://doi.org/10.1038/nature18956

640 Cabral, R.A., Jackson, M.G., Rose-Koga, E.F., Koga, K.T., Whitehouse, M.J., Antonelli, M.A.,

641 Farquhar, J., Day, J.M.D., Hauri, E.H., 2013. Anomalous sulphur isotopes in plume lavas reveal

642 deep mantle storage of Archaean crust. Nature 496, 490. https://doi.org/10.1038/nature12020

643 Carlson, R.W., Boyet, M., 2008. Composition of the Earth's interior: the importance of early events.

644 Philos. Trans. R. Soc. Math. Phys. Eng. Sci. 366, 4077-4103.

$645 \quad$ https://doi.org/10.1098/rsta.2008.0166

646 Carlson, R.W., Boyet, M., Horan, M., 2007. Chondrite Barium, Neodymium, and Samarium Isotopic 647 Heterogeneity and Early Earth Differentiation. Science 316, 1175-1178.

$648 \quad$ https://doi.org/10.1126/science.1140189

649 Caro, G., Bourdon, B., Halliday, A.N., Quitté, G., 2008. Super-chondritic Sm/Nd ratios in Mars, the 650 Earth and the Moon. Nature 452, 336-339. https://doi.org/10.1038/nature06760

651 Carpentier, M., Chauvel, C., Maury, R.C., Mattielli, N., 2009. The "zircon effect" as recorded by the 652 chemical and Hf isotopic compositions of Lesser Antilles forearc sediments. Earth Planet. Sci.

653 Lett. 287, 86-99. https://doi.org/10.1016/j.eps1.2009.07.043

654 Chase, C., Patchett, P., 1988. Stored mafic/ultramafic crust and early Archean mantle depletion. Earth 655 Planet. Sci. Lett. 91, 66-72. https://doi.org/10.1016/0012-821X(88)90151-3

656 Chauvel, C., Garçon, M., Bureau, S., Besnault, A., Jahn, B., Ding, Z., 2014. Constraints from loess on 657 the Hf-Nd isotopic composition of the upper continental crust. Earth Planet. Sci. Lett. 388, 48$658 \quad$ 58. https://doi.org/10.1016/j.epsl.2013.11.045

659 Chauvel, C., Lewin, E., Carpentier, M., Arndt, N.T., Marini, J.-C., 2008. Role of recycled oceanic 660 basalt and sediment in generating the Hf-Nd mantle array. Nat. Geosci. 1, 64-67. 
662 Dauphas, N., 2017. The isotopic nature of the Earth's accreting material through time. Nature 541, 521-524. https://doi.org/10.1038/nature20830

664

665

666

667

668

669

670

671

672

673

674

675

676

677

678

679

680

681

682

683

684

685

686

687

688

Dauphas, N., Pourmand, A., 2015. Thulium anomalies and rare earth element patterns in meteorites and Earth: Nebular fractionation and the nugget effect. Geochim. Cosmochim. Acta 163, 234261. https://doi.org/10.1016/j.gca.2015.03.037

Delavault, H., Chauvel, C., Thomassot, E., Devey, C.W., Dazas, B., 2016. Sulfur and lead isotopic evidence of relic Archean sediments in the Pitcairn mantle plume. Proc. Natl. Acad. Sci. 113, 12952. https://doi.org/10.1073/pnas. 1523805113

Dhuime, B., Hawkesworth, C.J., Cawood, P.A., Storey, C.D., 2012. A Change in the Geodynamics of Continental Growth 3 Billion Years Ago. Science 335, 1334. https://doi.org/10.1126/science.1216066

Dhuime, B., Hawkesworth, C.J., Delavault, H., Cawood, P.A., 2018. Rates of generation and destruction of the continental crust: implications for continental growth. Philos. Trans. R. Soc. Math. Phys. Eng. Sci. 376, 20170403. https://doi.org/10.1098/rsta.2017.0403

Dickin, A.P., 1987. Cerium isotope geochemistry of ocean island basalts. Nature 326, 283-284. https://doi.org/10.1038/326283a0

Goldstein, S.J., Jacobsen, S.B., 1988. Nd and Sr isotopic systematics of river water suspended material: implications for crustal evolution. Earth Planet. Sci. Lett. 87, 249-265. https://doi.org/10.1016/0012-821X(88)90013-1

Goldstein, S.L., O’Nions, R.K., Hamilton, P.J., 1984. A Sm-Nd isotopic study of atmospheric dusts and particulates from major river systems. Earth Planet. Sci. Lett. 70, 221-236. https://doi.org/10.1016/0012-821X(84)90007-4

Hawkesworth, C.J., Cawood, P.A., Dhuime, B., Kemp, T.I.S., 2017. Earth's Continental Lithosphere Through Time. Annu. Rev. Earth Planet. Sci. 45, 169-198. https://doi.org/10.1146/annurev-earth063016-020525

Holland, H.D., 2002. Volcanic gases, black smokers, and the great oxidation event. Geochim. Cosmochim. Acta 66, 3811-3826. https://doi.org/10.1016/S0016-7037(02)00950-X 
Jackson, M.G., Jellinek, A.M., 2013. Major and trace element composition of the high $3 \mathrm{He} / 4 \mathrm{He}$ mantle: Implications for the composition of a nonchonditic Earth. Geochem. Geophys. Geosystems 14, 2954-2976. https://doi.org/10.1002/ggge.20188

Jacobsen, S.B., Wasserburg, G.J., 1980. A two-reservoir recycling model for mantle-crust evolution. Proc. Natl. Acad. Sci. 77, 6298. https://doi.org/10.1073/pnas.77.11.6298

Javoy, M., 1995. The integral enstatite chondrite model of the Earth. Geophys. Res. Lett. 22, 22192222. https://doi.org/10.1029/95GL02015

Jones, R.E., van Keken, P.E., Hauri, E.H., Tucker, J.M., Vervoort, J., Ballentine, C.J., 2019. Origins of the terrestrial Hf-Nd mantle array: Evidence from a combined geodynamical-geochemical approach. Earth Planet. Sci. Lett. 518, 26-39. https://doi.org/10.1016/j.eps1.2019.04.015

Labanieh, S., Chauvel, C., Germa, A., Quidelleur, X., Lewin, E., 2010. Isotopic hyperbolas constrain sources and processes under the Lesser Antilles arc. Earth Planet. Sci. Lett. 298, 35-46. https://doi.org/10.1016/j.eps1.2010.07.018

Lyubetskaya, T., Korenaga, J., 2007. Chemical composition of Earth's primitive mantle and its variance: 1. Method and results. J. Geophys. Res. Solid Earth 112. https://doi.org/10.1029/2005JB004223

Makishima, A., Masuda, A., 1994. Ce isotope ratios of N-type MORB. Chem. Geol. 118, 1-8. https://doi.org/10.1016/0009-2541(94)90166-X

McDonough, W.F., Sun, S.-S., 1995. The composition of the Earth. Chem. Geol. 120, 223-253. https://doi.org/10.1016/0009-2541(94)00140-4

O’Neil, J., Carlson, R.W., 2017. Building Archean cratons from Hadean mafic crust. Science 355, 1199. https://doi.org/10.1126/science.aah3823

O’Neil, J., Carlson, R.W., Francis, D., Stevenson, R.K., 2008. Neodymium-142 Evidence for Hadean Mafic Crust. Science 321, 1828-1831. https://doi.org/10.1126/science.1161925

O’Neil, J., Carlson, R.W., Papineau, D., Levine, E.Y., Francis, D., 2019. Chapter 16 - The Nuvvuagittuq Greenstone Belt: A Glimpse of Earth's Earliest Crust, in: Van Kranendonk, M.J., Bennett, V.C., Hoffmann, J.E. (Eds.), Earth's Oldest Rocks (Second Edition). Elsevier, pp. 349374. https://doi.org/10.1016/B978-0-444-63901-1.00016-2 
O’Neil, J., Carlson, R.W., Paquette, J.-L., Francis, D., 2012. Formation age and metamorphic history of the Nuvvuagittuq Greenstone Belt. Precambrian Res. 220-221, 23-44. https://doi.org/10.1016/j.precamres.2012.07.009

O’Neil, J., Francis, D., Carlson, R.W., 2011. Implications of the Nuvvuagittuq Greenstone Belt for the Formation of Earth's Early Crust. J. Petrol. 52, 985-1009. https://doi.org/10.1093/petrology/egr014

O'Neill, H.St.C., Palme, H., 2008. Collisional erosion and the non-chondritic composition of the terrestrial planets. Philos. Trans. R. Soc. Math. Phys. Eng. Sci. 366, 4205-4238. https://doi.org/10.1098/rsta.2008.0111

Palme, H., O’Neill, H., 2014. Cosmochemical Estimates of Mantle Composition. Elsevier. https://doi.org/10.1016/B978-0-08-095975-7.00201-1

Plank, T., 2014. The chemical composition of subducting sediments. Treatise Geochem. 4, 607-629. https://doi.org/10.1016/b978-0-08-095975-7.00319-3

Pourmand, A., Dauphas, N., Ireland, T.J., 2012. A novel extraction chromatography and MC-ICP-MS technique for rapid analysis of REE, Sc and Y: Revising CI-chondrite and Post-Archean Australian Shale (PAAS) abundances. Chem. Geol. 291, 38-54. https://doi.org/10.1016/j.chemgeo.2011.08.011

Rudnick, R.L., Gao, S., 2003. Composition of the continental crust, in: Holland, H.D., Turekian, K.K. (Eds.), Treatise on Geochemistry. Pergamon, Oxford, pp. 1-64.

Salters, V.J.M., Stracke, A., 2004. Composition of the depleted mantle. Geochem. Geophys. Geosystems 5. https://doi.org/10.1029/2003GC000597

Shimizu, H., Tanaka, T., Masuda, A., 1984. Meteoritic 138Ce/142Ce ratio and its evolution. Nature 307, 251-252. https://doi.org/10.1038/307251a0

Tanaka, T., Shimizu, H., Kawata, Y., Masuda, A., 1987. Combined La-Ce and Sm-Nd isotope systematics in petrogenetic studies. Nature $327,113-117$. https://doi.org/10.1038/327113a0

742 Tanimizu, M., 2000. Geophysical determination of the 138 La $\beta$ - decay constant. Phys. Rev. C 62, 017601. https://doi.org/10.1103/PhysRevC.62.017601

744 Taylor, S.R., McLennan, S.M., 1995. The geochemical evolution of the continental crust. Rev. 

766 according to the CHUR references defined for Ce in this study as $\varepsilon \mathrm{Ce}=\left(\frac{{ }^{138} \mathrm{Ce}}{\frac{{ }^{142} \mathrm{Ce}}{\text { sample }}}-1\right) \times 10,000$ 767 and for $\mathrm{Nd}$ by Bouvier et al. (2008) as $\varepsilon \mathrm{Nd}=\left(\frac{\frac{143_{\mathrm{Nd}}}{144 \mathrm{Nd}} \text { sample }}{\frac{143_{\mathrm{Nd}}}{144 \mathrm{Nd}} \mathrm{CHUR}}-1\right) \times 10,000$. Errors correspond to internal errors (2se).

Tazoe, H., Obata, H., Gamo, T., 2007. Determination of cerium isotope ratios in geochemical samples using oxidative extraction technique with chelating resin. J. Anal. At. Spectrom. 22, 616. https://doi.org/10.1039/b617285g

Vervoort, J.D., Patchett, P.J., Albarède, F., Blichert-Toft, J., Rudnick, R., Downes, H., 2000. Hf-Nd isotopic evolution of the lower crust. Earth Planet. Sci. Lett. 181, 115-129. https://doi.org/10.1016/S0012-821X(00)00170-9

Willig, M., Stracke, A., 2019. Earth’s chondritic light rare earth element composition: Evidence from the $\mathrm{Ce}-\mathrm{Nd}$ isotope systematics of chondrites and oceanic basalts. Earth Planet. Sci. Lett. 509, 5565. https://doi.org/10.1016/j.eps1.2018.12.004

Workman, R.K., Hart, S.R., 2005. Major and trace element composition of the depleted MORB mantle (DMM). Earth Planet. Sci. Lett. 231, 53-72. https://doi.org/10.1016/j.eps1.2004.12.005

Zindler, A., Hart, S., 1986. Chemical geodynamics. Annu. Rev. Earth Planet. Sci. 14, 493-571. https://doi.org/10.1146/annurev.ea.14.050186.002425

\section{Table captions}

Table $1 .{ }^{138} \mathrm{Ce} /{ }^{142} \mathrm{Ce}$ and ${ }^{143} \mathrm{Nd} /{ }^{144} \mathrm{Nd}$ isotopic ratios and $\mathrm{La} / \mathrm{Ce}$ and $\mathrm{Sm} / \mathrm{Nd}$ ratios of whole-rock OIBs, MORBs and loesses. The $\mathrm{Nd}$ isotopic compositions of loess and Kerguelen samples (*) are from Chauvel et al. (2014) and unpublished data from B. Moine, respectively. Epsilon values are normalised 
Table $2 .{ }^{138} \mathrm{Ce} /{ }^{142} \mathrm{Ce}$ isotopic ratios and $\mathrm{La} / \mathrm{Ce}$ whole-rock chondrites. Epsilon values are normalised

771 according to the CHUR references defined for Ce in this study as $\varepsilon \mathrm{Ce}=\left(\frac{\frac{{ }^{138} \mathrm{Ce}}{142 \mathrm{Ce}} \text { sample }}{\frac{138 \mathrm{Ce}}{{ }^{142} \mathrm{Ce}} \mathrm{CHUR}}-1\right) \times 10,000$.

772 Errors correspond to internal errors (2se).

773

774

775

776

777

778

779

780

781

782

783

784

785

786

787

788

789

790

791

792

793

794

Table 3. Elemental and isotopic compositions of Earth's main silicate reservoirs used in our calculations: BSE, bulk silicate Earth; EDR, early depleted reservoir; DMM, depleted MORB mantle; CC, continental crust; UCC, upper continental crust; and mafic crust. Errors are errors on data averages. No errors are given for model-based isotopic compositions (EDR, aged UCC, and mafic crust). Values in italics refer to literature data: CC Ce and Nd concentrations are from Rudnick and Gao (2003), concentrations for the mafic crust are those measured in PC-162 from O'Neil et al., (2011), and BSE ${ }^{143} \mathrm{Nd} /{ }^{144} \mathrm{Nd}$ ratios are from Bouvier et al. (2008). BSE range of Ce and Nd concentrations are modelled using Lu contents from Allègre et al. (2001), Lyubetskaya and Korenaga (2007), McDonough and Sun (1995), Palme and O’Neill (2014) and chondritic REE ratios (see supplementary material S4 for more details). Ce/Nd of the BSE is constant and set to 1.28 (1.22 for EDR). DMM isotopic composition is the mean value of data from this study, Bellot et al., 2015, 2018, Makishima and Masuda, 1994 and Willig and Stracke, 2019. UCC (1.8 Ga) Ce and Nd contents and isotopic compositions are the mean values of loess data from this study. UCC (2.2 Ga) isotopic compositions are calculated by aging $1.8 \mathrm{Ga}$ UCC.

\section{Figure captions}

Fig. 1. A) ${ }^{138} \mathrm{Ce} /{ }^{142} \mathrm{Ce}$ ratios measured in enstatite (green squares), ordinary (red diamonds), and carbonaceous (black triangles) chondrites. Literature values are from Bellot et al. (2015, 'B et al. 15') and Willig and Stracke (2019, 'W\&S19'). Data from the literature are normalised to the Ce $\mathrm{LmV}_{\mathrm{Lm}}$ reference material from this study: ${ }^{138} \mathrm{Ce} /{ }^{142} \mathrm{Ce}_{\mathrm{CeLmV}} /{ }^{138} \mathrm{Ce} /{ }^{142} \mathrm{Ce}$ CeAmes $=0.02257053 / 0.02257426$ (Bonnand et al., 2019). B) $\varepsilon$ Ce ratios vs. La/Ce ratios of chondrites from Willig and Stracke (2019) and this study. Data 
are normalised to the CHUR reference defined in these studies. The dashed line represents the $4.568 \mathrm{Ga}$

CHUR reference isochron.

Fig. 2. $\varepsilon N d$ vs. $\varepsilon C e$ of mantle-derived samples and loesses from this study (coloured symbols). Nd isotopic compositions of loess and Kerguelen samples are from Chauvel et al. (2014) and B. Moine (unpublished data), and Ce and Nd isotopic compositions of Gough samples are from Boyet et al. (2019). Literature data are in grey (Bellot et al., 2015, 2018; Makishima and Masuda, 1994; Willig and Stracke, 2019). Error bars are 2 se (internal error). Literature data are reported considering the epsilon values and CHUR references measured in each study to limit any bias introduced by normalisation. The data from Tanaka et al. (1987) are not included because we do not have the corresponding CHUR reference. The mantle array is defined by regression on mantle-derived samples only. Its equation defined from 134 data is $\varepsilon N d=-7.3( \pm 0.5) \times \varepsilon \mathrm{Ce}+0.4( \pm 0.3)$ (calculated with Isoplot ${ }^{\circledR}$ and considering errors of 0.25 and 0.10 for $\varepsilon \mathrm{Ce}$ and $\varepsilon \mathrm{Nd}$, respectively).

808

Fig. 3. REE patterns normalised to a chondritic primitive mantle for a chondritic BSE model (orange) and an EDR model with $\mathrm{Sm} / \mathrm{Nd}=\mathrm{Sm} / \mathrm{Nd}_{\mathrm{BSE}}+3.6 \%$ (green). The EDR REE pattern is calculated as follows. 1) The REE patterns are anchored at $\mathrm{Lu}$, the least incompatible REE. 2) The early depleted $\varepsilon \mathrm{Nd}_{\text {present }}$ value is calculated using the initial CHUR value (Bouvier et al., 2008) at $4.568 \mathrm{Ga}$ and a $\mathrm{Sm} / \mathrm{Nd}$ ratio $3.6 \%$ above that of the BSE. 3) The early depleted ${ }^{177} \mathrm{Hf} /{ }^{176} \mathrm{Hf}$ ratio is deduced from the Hf-Nd mantle correlation $\left(\varepsilon \mathrm{Hf}_{\text {present }}=1.59 \times \varepsilon \mathrm{Nd}_{\text {present }}+1.28\right.$; Chauvel et al., 2008). 4) The Lu/Hf ratio is obtained by comparison of the initial ${ }^{177} \mathrm{Hf} /{ }^{176} \mathrm{Hf}$ CHUR ratio (Bouvier et al., 2008) and the early depleted

816 Hf isotopic composition calculated in step 3. That is, the Hf concentration is obtained from the known

817 Lu concentration set as the anchor point in step 1.5) The Sm concentration is calculated from the Sm/Hf 818 ratio, which has a constant value of 1.44 in OIBs (Jackson and Jellinek, 2013). 6) The Nd concentration 819 is calculated from the $\mathrm{Sm} / \mathrm{Nd}$ ratio (known after steps 2 and 5). 7) The La and Ce concentrations are 820 calculated using a binomial fit through the chondrite normalised $\mathrm{Sm}, \mathrm{Nd}$, and $\mathrm{Lu}$ concentrations (i.e., 821 the equation of the La-Lu pattern is of the form $y=a x^{2}+b x+c$, where $x$ represents the REEs, numbered $1-15$ for $\mathrm{La}-\mathrm{Lu})$. 
824 Fig. 4. $\varepsilon N d$ vs. $\varepsilon$ Ce measured in mantle-derived samples (see Fig. 2, with additional data for IABs from 825 Bellot et al., 2015, 2018 and continental crust samples; see Supplementary Fig. S6). The global linear 826 trend of the mantle array is shown as the black dashed line and intercepts the chondritic composition $827(\varepsilon \mathrm{Nd}=0.00, \varepsilon \mathrm{Ce}=0.07 \pm 0.05(2 \sigma))$. Large symbols represent terrestrial reservoirs. Note that mean 828 loess corresponds to a $1.8 \mathrm{Ga} \mathrm{UCC}\left(\mathrm{T}_{\mathrm{DM}}\right)$; and we represent a $2.2 \mathrm{Ga} \mathrm{UCC}$ as a modelled composition 829 (aged loess). The mean CC value is the mean value of continental samples averaged by location. The 830 continental crust value published in Tanaka et al. (1987) is calculated from 5 measurements. The $4.3 \mathrm{Ga}$ 831 mafic crust composition results from an extraction model from the depleted mantle. The red field 832 represents the DMM-UCC mixing curves. The brown field corresponds to the DMM-4.3 Ga mafic crust 833 mixing curves. The fields correspond to the different curves calculated using DMM Ce and $\mathrm{Nd}$ concentrations given by Salters and Stracke, 2004 and Workman and Hart, 2005. The orange field represents all the DMM-CC mixing curves calculated for a chondritic BSE model (bulk crust compositions shown by the bold orange line). The green field represents all the DMM-CC mixing curves calculated for an EDR model (bulk crust compositions shown by the bold green line). See details in the text and calculation parameters in Table 3.

Fig. 5. Mass fraction of the depleted mantle relative to the primitive mantle $\left(\mathrm{m}_{\mathrm{DM}} / \mathrm{m}_{\mathrm{PM}}\right.$, expressed in percent) vs. the $\varepsilon N d$ value of the bulk continental crust. Two cases are represented: DMM-CC mixing

842 for a chondritic BSE (orange) and DMM-CC mixing for an EDR (green). Parameters used in the 843 calculations are discussed in the text and reported in Table 3.

845 Fig. 6. $\varepsilon N d$ vs. $\varepsilon$ Ce measured in mantle-derived samples compared with reservoir evolution models. The present-day average compositions of the recycled oceanic crust (ROC = MORB; this study) and oceanic sediments (Bellot et al., 2015, 2018) are shown as large symbols. Solid lines outline the present-day

848 isotopic compositions of these reservoirs if formed at different ages. The yellow line shows the evolution 849 of MORBs using mean $\mathrm{La} / \mathrm{Ce}$ and $\mathrm{Sm} / \mathrm{Nd}$ ratios of MORBs and the MORB source. Similarly, the blue 850 and purple lines show the evolution of oceanic sediments with chondrite-normalised REE patterns 
851 showing a Ce negative anomaly as observed in modern oceanic sediments $(\mathrm{La} / \mathrm{Ce}=0.57)$ or without a

852 Ce anomaly $(\mathrm{La} / \mathrm{Ce}=0.47)$, representing oceanic sediments formed in reduced conditions before the 853 GOE ( $\sim 2.4 \mathrm{Ga})$, respectively. The Ce-Nd isotopic composition of the recycled material is shown by 854 mixing curves between contemporaneous ROC and oceanic sediments (dashed lines). 


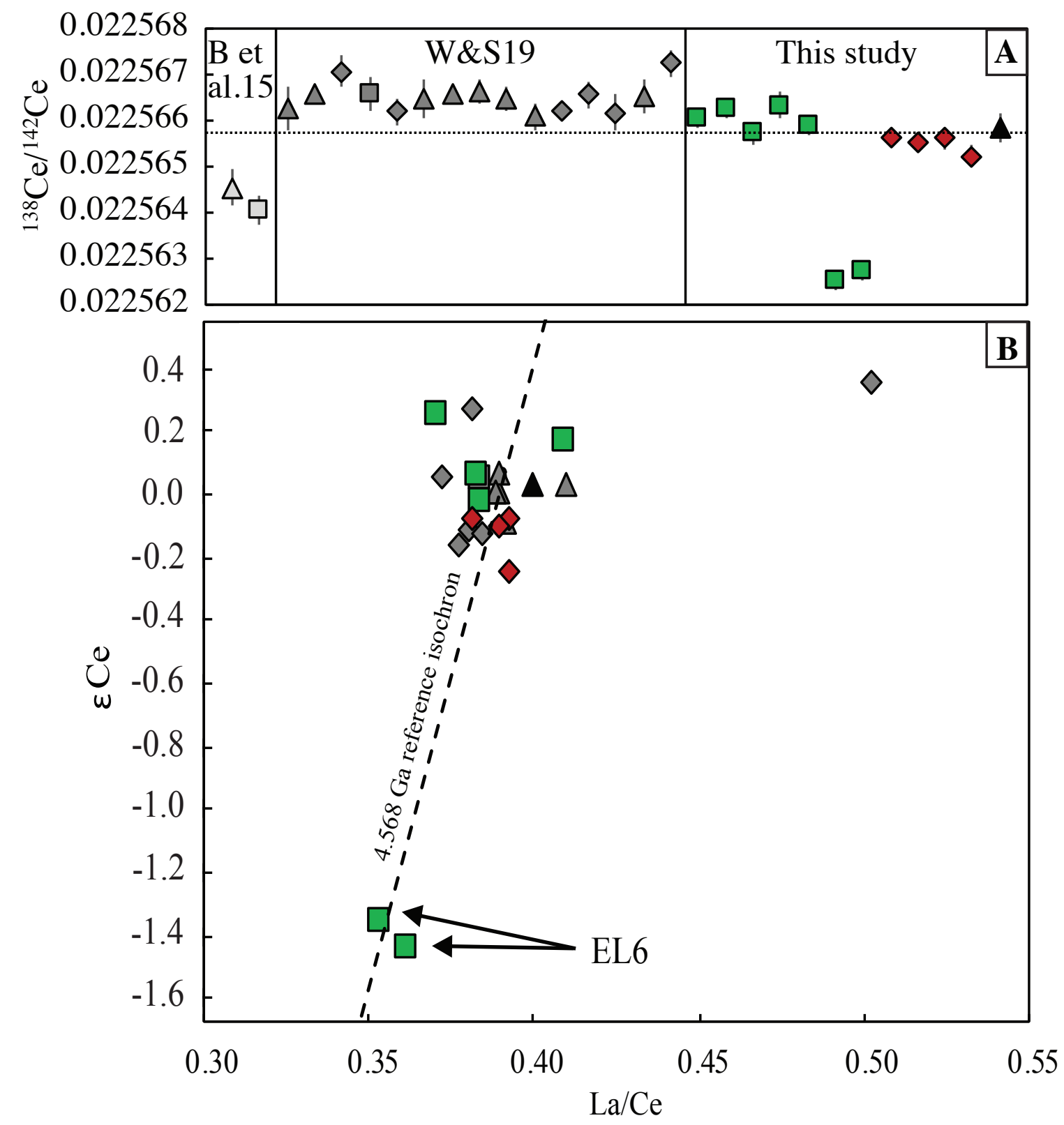

Fig.1 


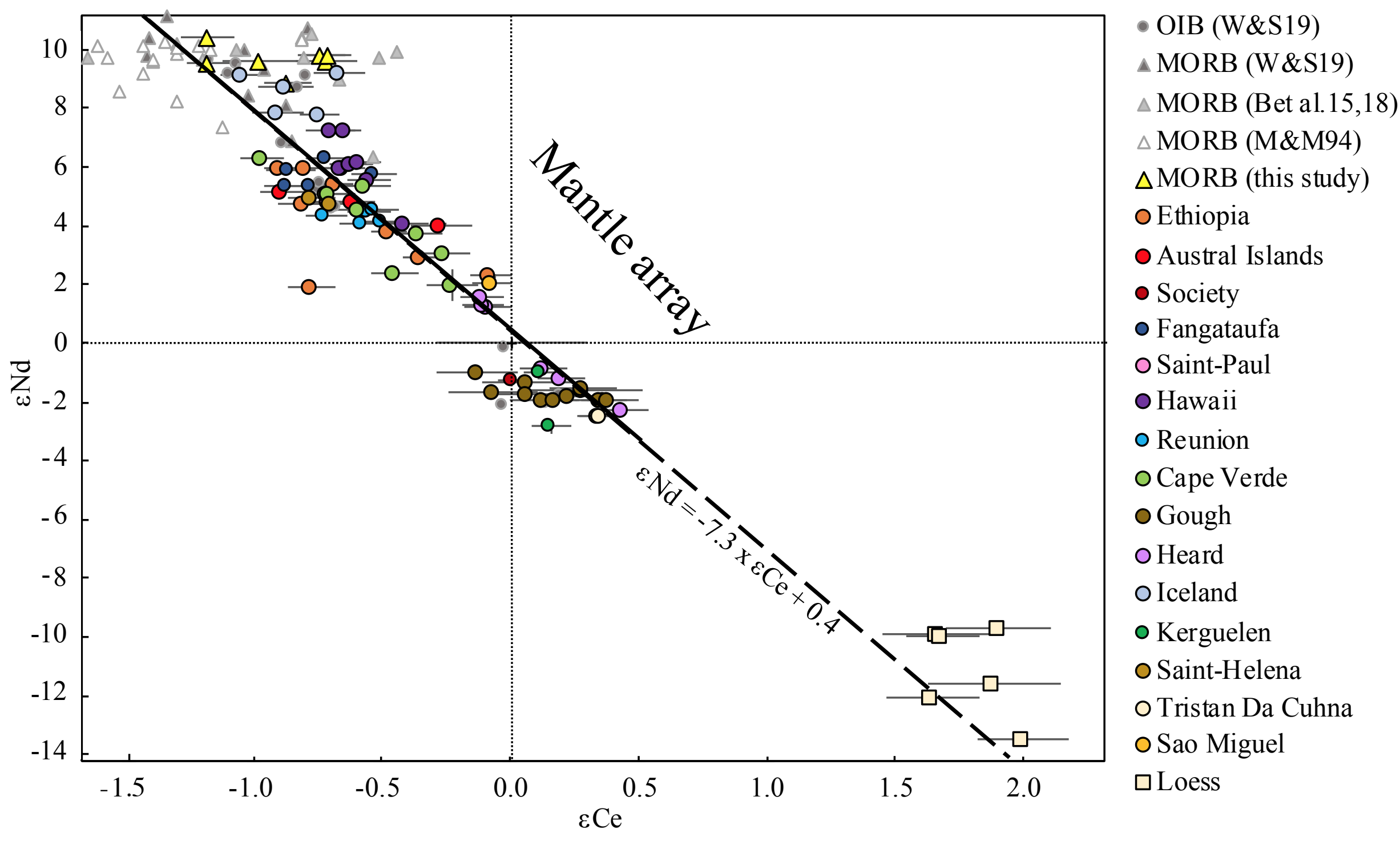

Fig.2 


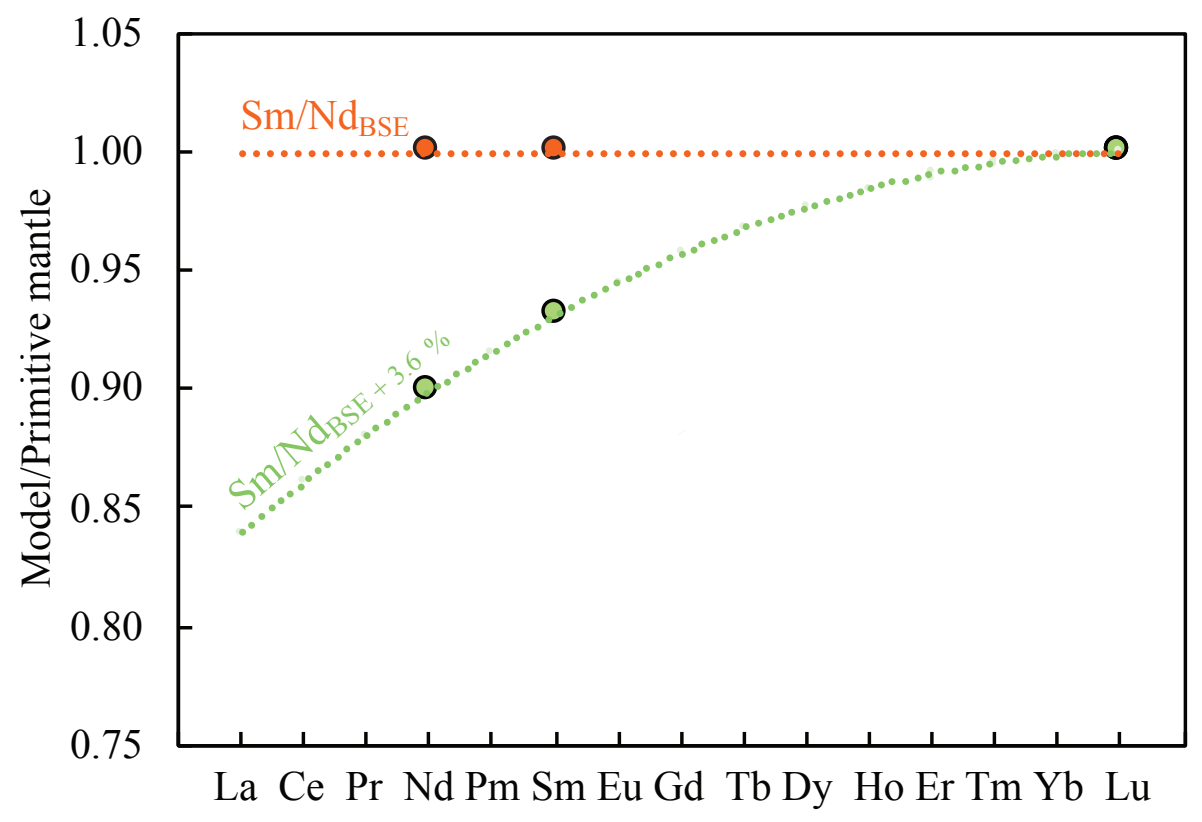

Fig. 3 


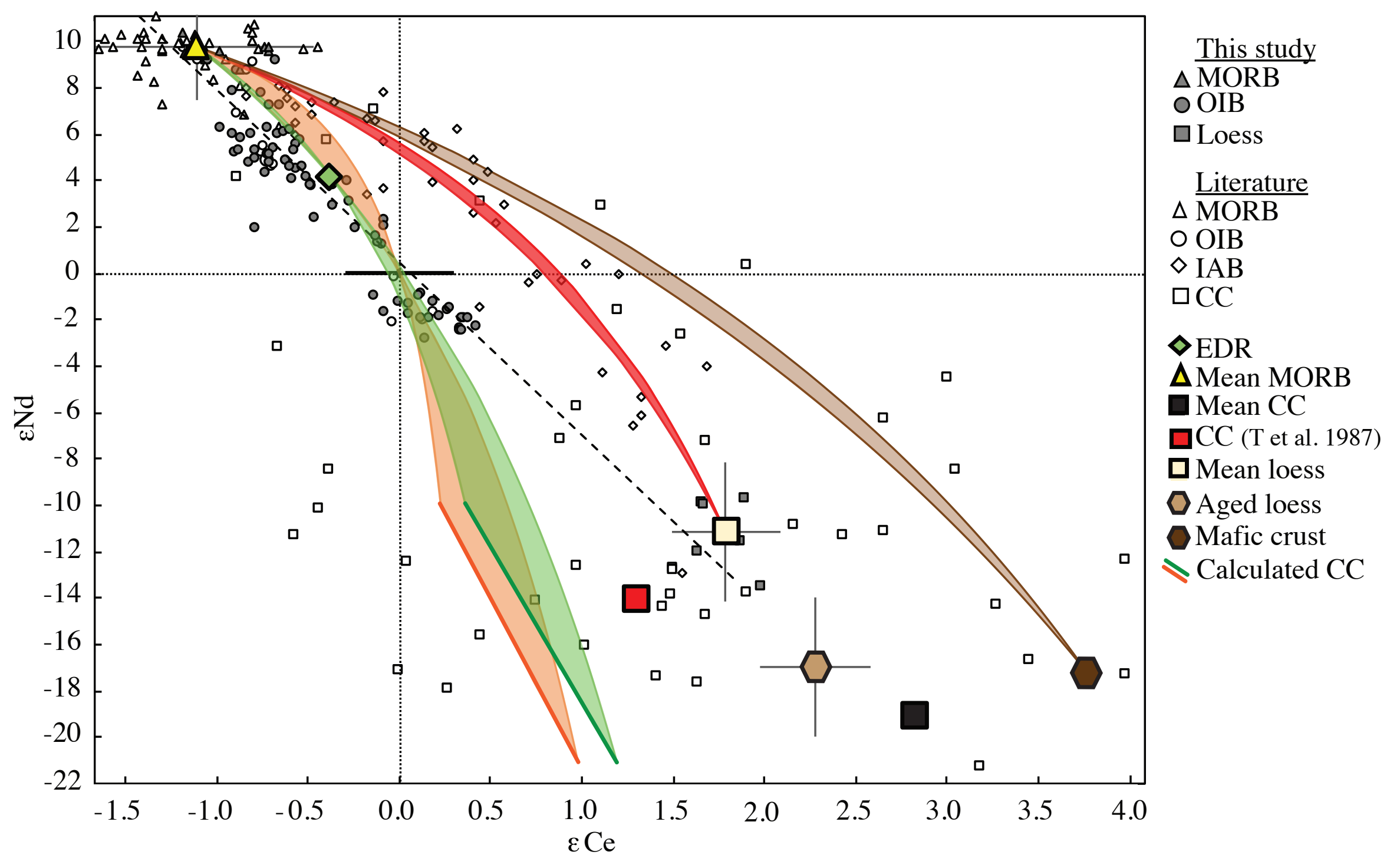

Fig.4 


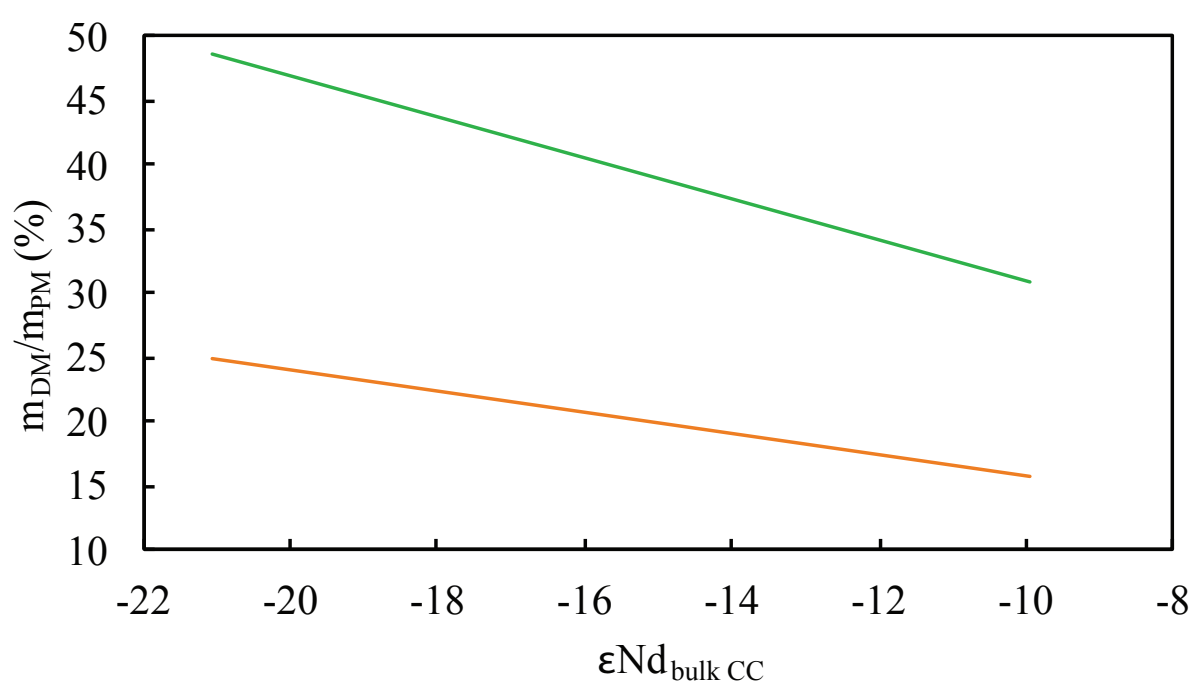

Fig.5 


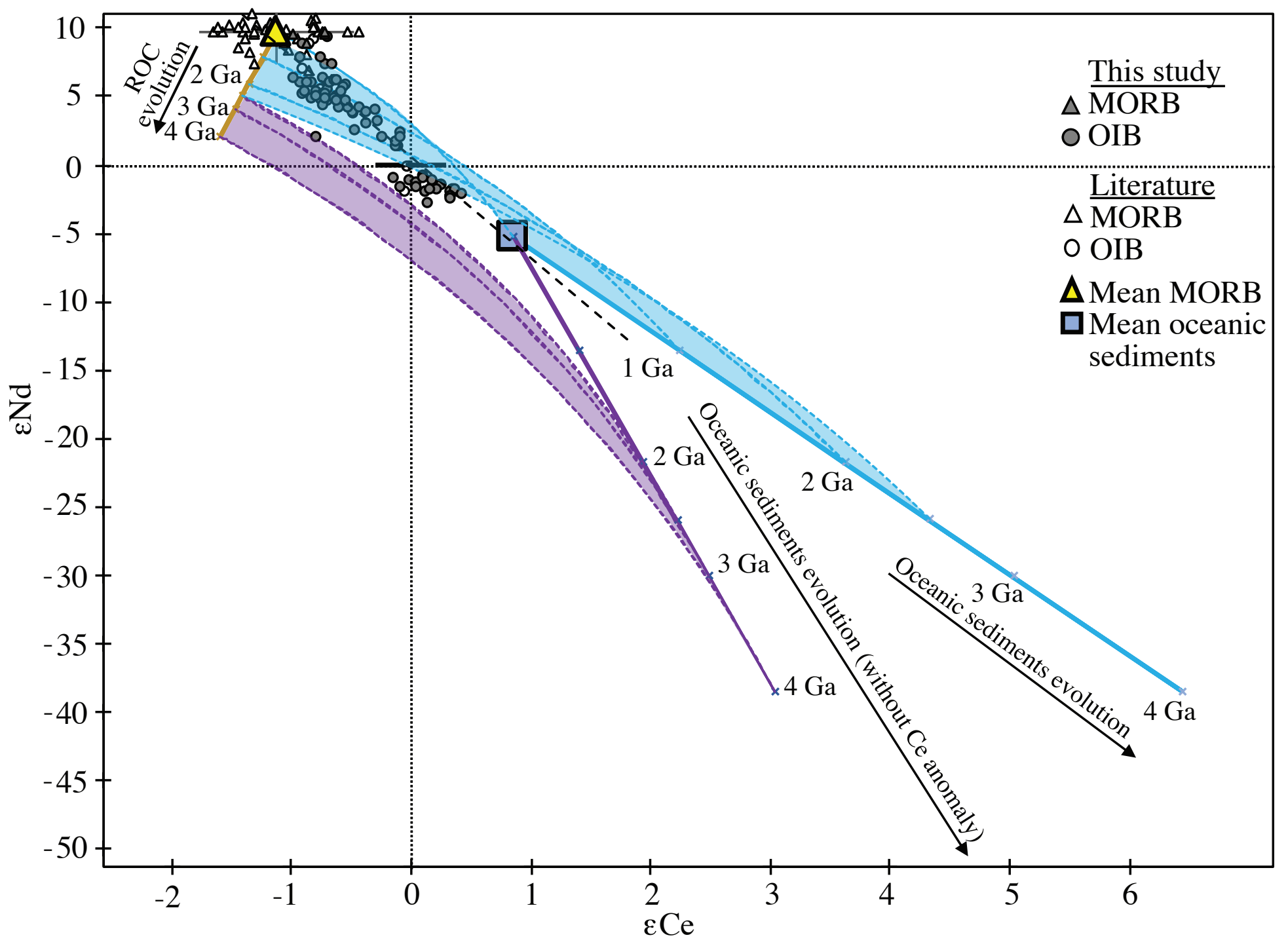

Fig.6 


\begin{tabular}{|c|c|c|c|c|c|c|c|c|c|c|c|}
\hline Type & Sample & Location & Volcano & ${ }^{138} \mathrm{Ce} /{ }^{142} \mathrm{Ce}$ & 2 se & $\varepsilon \mathrm{Ce}$ & $\mathrm{La} / \mathrm{Ce}$ & ${ }^{143} \mathrm{Nd} /{ }^{144} \mathrm{Nd}$ & 2 se & $\varepsilon \mathbf{N d}$ & $\mathrm{Sm} / \mathrm{Nd}$ \\
\hline \multirow[t]{59}{*}{ OIB } & E38 & Ethiopia & & 0.02256395 & 20 & -0.81 & 0.305 & 0.512935 & 2 & 5.95 & 0.220 \\
\hline & E39 & & & 0.02256372 & 14 & -0.91 & 0.318 & 0.512936 & 2 & 5.96 & 0.218 \\
\hline & E95 & & & 0.02256393 & 21 & -0.81 & 0.318 & 0.512871 & 2 & 4.71 & 0.273 \\
\hline & E156 & & & 0.02256421 & 16 & -0.69 & 0.375 & 0.512907 & 2 & 5.40 & 0.190 \\
\hline & E202 & & & 0.02256401 & 20 & -0.78 & 0.310 & 0.512728 & 2 & 1.92 & 0.257 \\
\hline & E266 & & & 0.02256469 & 16 & -0.48 & 0.399 & 0.512824 & 1 & 3.78 & 0.199 \\
\hline & E268 & & & 0.02256497 & 16 & -0.35 & 0.459 & 0.512779 & 1 & 2.90 & 0.209 \\
\hline & E271 & & & 0.02256558 & 18 & -0.08 & 0.478 & 0.512746 & 2 & 2.26 & 0.205 \\
\hline & RRTO 06 & Austral Islands & Rututu & 0.02256437 & 19 & -0.62 & 0.474 & 0.512877 & 2 & 4.81 & 0.208 \\
\hline & TBA-IH & & Tubuai & 0.02256375 & 20 & -0.89 & 0.355 & 0.512894 & 2 & 5.15 & 0.193 \\
\hline & MCD201 & & McDonald & 0.02256514 & 27 & -0.28 & 0.145 & 0.512834 & 2 & 3.98 & 0.280 \\
\hline & $13 \mathrm{~K}$ & Society & Tahaa & 0.02256578 & 14 & 0.00 & 0.361 & 0.512563 & 2 & -1.30 & 0.261 \\
\hline & F107 & Tuamotu & & 0.02256382 & 22 & -0.86 & 0.440 & 0.512929 & 2 & 5.83 & 0.236 \\
\hline & F124 & & & 0.02256379 & 21 & -0.87 & 0.443 & 0.512902 & 2 & 5.30 & 0.219 \\
\hline & F128 & & Fangataufa & 0.02256456 & 20 & -0.53 & 0.460 & 0.512923 & 1 & 5.73 & 0.239 \\
\hline & F129 & & & 0.02256415 & 20 & -0.72 & 0.436 & 0.512951 & 2 & 6.25 & 0.229 \\
\hline & F176 & & & 0.02256400 & 25 & -0.78 & 0.494 & 0.512902 & 2 & 5.31 & 0.210 \\
\hline & SP1 & St-Paul & & 0.02256416 & 16 & -0.71 & 0.445 & 0.512876 & 2 & 4.79 & 0.251 \\
\hline & $1804-1$ & Hawaii & Loihi & 0.02256428 & 15 & -0.66 & 0.295 & 0.512934 & 1 & 5.94 & 0.249 \\
\hline & $1804-21$ & & & 0.02256427 & 20 & -0.66 & 0.308 & 0.512935 & 2 & 5.96 & 0.240 \\
\hline & 1804-19 & & & 0.02256435 & 19 & -0.63 & 0.275 & 0.512940 & 1 & 6.04 & 0.247 \\
\hline & Haw-2000-04 & & Mauna Loa & 0.02256451 & 20 & -0.55 & 0.387 & 0.512913 & 1 & 5.52 & 0.282 \\
\hline & Haw-2000-19 & & & 0.02256483 & 20 & -0.41 & 0.401 & 0.512838 & 2 & 4.06 & 0.270 \\
\hline & Haw-2000-13 & & Kohala & 0.02256417 & 22 & -0.71 & 0.417 & 0.512999 & 1 & 7.20 & 0.214 \\
\hline & Haw-2000-28 & & Kilauea & 0.02256442 & 20 & -0.60 & 0.407 & 0.512944 & 2 & 6.13 & 0.285 \\
\hline & Haw-2000-17 & & Mauna Kea & 0.02256430 & 15 & -0.65 & 0.414 & 0.513000 & 1 & 7.21 & 0.233 \\
\hline & $0608-021$ & Reunion & Piton de la & 0.02256414 & 19 & -0.72 & 0.436 & 0.512851 & 2 & 4.32 & 0.236 \\
\hline & $80-76$ & & Fournaise & 0.02256463 & 18 & -0.50 & 0.446 & 0.512841 & 2 & 4.11 & 0.229 \\
\hline & $989 / 036$ & & & 0.02256450 & 19 & -0.56 & 0.445 & 0.512859 & 2 & 4.46 & 0.242 \\
\hline & $986 / 115$ & & & 0.02256445 & 20 & -0.58 & 0.440 & 0.512837 & 2 & 4.03 & 0.230 \\
\hline & 070406-1 & & & 0.02256457 & 20 & -0.53 & 0.429 & 0.512862 & 2 & 4.53 & 0.250 \\
\hline & $67 \mathrm{a}$ & Cape Verde & Fogo & 0.02256517 & 23 & -0.26 & 0.459 & 0.512786 & 1 & 3.03 & 0.175 \\
\hline & F10 & & & 0.02256524 & 23 & -0.23 & 0.475 & 0.512730 & 3 & 1.94 & 0.179 \\
\hline & F16 & & & 0.02256473 & 20 & -0.46 & 0.466 & 0.512752 & 2 & 2.37 & 0.185 \\
\hline & CY-165 & & & 0.02256448 & 23 & -0.57 & 0.421 & 0.512901 & 1 & 5.30 & 0.186 \\
\hline & SV-01 & & Sao Vicente & 0.02256415 & 20 & -0.72 & 0.456 & 0.512890 & 1 & 5.08 & 0.191 \\
\hline & SV-12 & & & 0.02256417 & 22 & -0.71 & 0.479 & 0.512889 & 2 & 5.05 & 0.202 \\
\hline & S-06 & & Sal & 0.02256442 & 20 & -0.60 & 0.469 & 0.512862 & 2 & 4.53 & 0.214 \\
\hline & SN-09 & & Sao Nicolau & 0.02256356 & 19 & -0.98 & 0.481 & 0.512952 & 2 & 6.29 & 0.190 \\
\hline & ST08 & & Santiago & 0.02256495 & 21 & -0.36 & 0.486 & 0.512822 & 1 & 3.74 & 0.200 \\
\hline & $93(07) 77$ & Iceland & Höfudreidarm & 0.02256424 & 22 & -0.67 & 0.336 & 0.513102 & 1 & 9.20 & 0.188 \\
\hline & $93(07) 76$ & & úli & 0.02256377 & 24 & -0.88 & 0.359 & 0.513077 & 1 & 8.71 & 0.381 \\
\hline & $93(07) 24$ & & Asbyrgi & 0.02256408 & 17 & -0.75 & 0.377 & 0.513027 & 2 & 7.74 & 0.352 \\
\hline & $93(07) 23$ & & & 0.02256371 & 22 & -0.91 & 0.372 & 0.513030 & 2 & 7.81 & 0.285 \\
\hline & $93(07) 56$ & & Langaviti & 0.02256340 & 20 & -1.05 & 0.350 & 0.513097 & 1 & 9.12 & 0.298 \\
\hline & ACO 95-3 & Sao Miguel & & 0.02256559 & 17 & -0.08 & 0.479 & 0.512733 & 1 & 2.00 & 0.190 \\
\hline & BM1962 128 (114) & Tristan Da Cunha & & 0.02256653 & 19 & 0.34 & 0.448 & 0.512503 & 2 & -2.47 & 0.178 \\
\hline & BM1962 128 (112) & & & 0.02256654 & 18 & 0.34 & 0.489 & 0.512502 & 1 & -2.49 & 0.178 \\
\hline & BM1965 P5 (8) & St-Helena & & 0.02256401 & 21 & -0.78 & 0.741 & 0.512884 & 2 & 4.95 & 0.201 \\
\hline & BM1965 P5 (12) & & & 0.02256417 & 18 & -0.71 & 0.433 & 0.512872 & 2 & 4.73 & 0.208 \\
\hline & 65001 & Heard & & 0.02256604 & 20 & 0.12 & 0.456 & 0.512586 & 2 & -0.87 & 0.203 \\
\hline & 65151 & & & 0.02256674 & 22 & 0.43 & 0.468 & 0.512512 & 1 & -2.31 & 0.198 \\
\hline & 65171 & & & 0.02256620 & 21 & 0.19 & 0.545 & 0.512567 & 1 & -1.23 & 0.188 \\
\hline & 69230 & & & 0.02256555 & 22 & -0.09 & 0.491 & 0.512691 & 3 & 1.19 & 0.184 \\
\hline & 69244 & & & 0.02256551 & 18 & -0.11 & 0.464 & 0.512697 & 2 & 1.30 & 0.196 \\
\hline & 69254 & & & 0.02256550 & 20 & -0.12 & 0.463 & 0.512711 & 2 & 1.57 & 0.195 \\
\hline & LVF-98-107 & Kerguelen & & 0.02256577 & 23 & 0.00 & & & & & \\
\hline & MPC-99-103 & & & 0.02256611 & 17 & 0.15 & & $0.512484 *$ & $12 *$ & -2.85 & \\
\hline & RR08-121 & & & 0.02256603 & 17 & 0.12 & & $0.512579 *$ & $2 *$ & -0.99 & \\
\hline \multirow[t]{7}{*}{ MORB } & Searise-1 DR05-102 & MORB & Pacific Ocean & 0.02256309 & 23 & -1.19 & 0.310 & 0.513164 & 2 & 10.42 & 0.349 \\
\hline & MD23 Site 4 & & & 0.02256380 & 21 & -0.87 & 0.289 & 0.513084 & 1 & 8.85 & 0.308 \\
\hline & Clipperton DR01 & & & 0.02256355 & 33 & -0.98 & 0.343 & 0.513122 & 2 & 9.59 & 0.321 \\
\hline & CY82-0903 & & & 0.02256310 & 20 & -1.18 & 0.391 & 0.513118 & 1 & 9.52 & 0.278 \\
\hline & MD34-D3 & & Indian Ocean & 0.02256414 & 27 & -0.72 & 0.297 & 0.513122 & 2 & 9.60 & 0.393 \\
\hline & MD34-D4 & & & 0.02256409 & 22 & -0.74 & 0.372 & 0.513133 & 1 & 9.81 & 0.336 \\
\hline & MD34-D6 & & & 0.02256416 & 20 & -0.71 & 0.411 & 0.513133 & 1 & 9.81 & 0.305 \\
\hline \multirow[t]{6}{*}{ Loess } & R11 & W Europe & Belgium & 0.02257001 & 59 & 1.88 & & $0.512035^{*}$ & $9^{*}$ & -11.61 & \\
\hline & LO94 & & Svalbard & 0.02257026 & 40 & 1.99 & & $0.511937 *$ & $10 *$ & -13.52 & \\
\hline & $\mathrm{XN}-4$ & China & Xining & 0.02256952 & 50 & 1.66 & & $0.512120 *$ & $11^{*}$ & -9.95 & \\
\hline & Sahara $2900 \mathrm{~m}$ & Sahara & Alpes, France & 0.02256946 & 41 & 1.64 & & $0.512011 *$ & $7 *$ & -12.07 & \\
\hline & TJK3198 & Tajikistan & Chashmanigar & 0.02257004 & 46 & 1.89 & & $0.512131^{*}$ & $8^{*}$ & -9.73 & \\
\hline & TJK3165 & & & 0.02256955 & 32 & 1.68 & & $0.512117 *$ & $9 *$ & -10.01 & \\
\hline
\end{tabular}




\begin{tabular}{lcccccc} 
Sample & Location & Type & ${ }^{138} \mathbf{C e} /{ }^{142} \mathbf{C e}$ & $\mathbf{2 s e}$ & $\boldsymbol{\varepsilon}$ Ce & $\mathbf{L a} / \mathbf{C e}$ \\
\hline Sahara 97072 & Sahara & EH3 - Find & 0.02256613 & 21 & 0.16 & 0.410 \\
Sahara 97158 & Sahara & EH3 - Find & 0.02256571 & 24 & -0.02 & 0.385 \\
Oudiyat Sbaa & W Sahara & EH5 - Fall & 0.02256633 & 26 & 0.25 & 0.371 \\
Adrar Bous & Niger & EL5 - Find & 0.02256591 & 21 & 0.06 & 0.384 \\
Yilmia & Australia & EL6 - Find & 0.02256251 & 20 & -1.44 & 0.362 \\
Pillistfer & Estonia & EL6 - Fall & 0.02256272 & 20 & -1.35 & 0.354 \\
Agen & France & H5 - Find & 0.02256561 & 21 & -0.07 & 0.393 \\
NWA 8007 & Morocco & L3 - Find & 0.02256554 & 20 & -0.10 & 0.389 \\
NWA 10854 & NW Africa & L3 - Find & 0.02256560 & 23 & -0.07 & 0.382 \\
Saint-Severin & France & LL6 - Fall & 0.02256522 & 23 & -0.24 & 0.392 \\
Allende & Mexico & CV3 - Fall & 0.02256585 & 32 & 0.20 & 0.400
\end{tabular}




\begin{tabular}{l|c|c|c|c|c|c|c|} 
& Chondritic BSE & EDR & DMM & CC & UCC (1.8 Ga) & UCC (2.2 Ga) & Mafic crust (4.3 Ga) \\
\hline $\mathbf{C e}(\boldsymbol{\mu g} / \mathbf{g})$ & $1.0-1.7$ & & & 43 & 68 & 68 & 11.2 \\
$\mathbf{N d}(\boldsymbol{\mu g} / \mathbf{g})$ & $0.8-1.3$ & & & 20 & 29 & 29 & 5.9 \\
$\mathbf{C e} / \mathbf{N d}$ & 1.28 & 1.22 & & 2.15 & 2.33 & 2.33 & 1.9 \\
${ }^{138} \mathbf{C e} /{ }^{142} \mathbf{C e}$ & $0.02256577 \pm 66$ & 0.02256492 & $0.02256325 \pm 145$ & & $0.02256981 \pm 68$ & 0.02257091 & 0.0225743 \\
$\mathbf{\varepsilon} \mathbf{C e}$ & $0.00 \pm 0.29$ & -0.4 & $-1.1 \pm 0.6$ & & $1.8 \pm 0.3$ & 2.3 & 3.8 \\
${ }^{143} \mathbf{N d} /{ }^{144} \mathbf{N d}$ & $0.512630 \pm 11$ & 0.512842 & $0.513129 \pm 116$ & & $0.512059 \pm 155$ & 0.511759 & 0.511745 \\
$\mathbf{8 N d}$ & $0.00 \pm 0.21$ & 4.1 & $9.7 \pm 2.3$ & & $-11.2 \pm 3.0$ & -17 & -17.3
\end{tabular}




\section{Supplementary material}

Formation of the Ce-Nd mantle array: crustal extraction vs. recycling by subduction

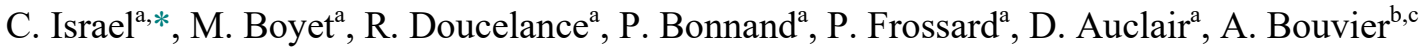

${ }^{a}$ Université Clermont Auvergne, CNRS, IRD, OPGC, Laboratoire Magmas et Volcans, F-63000

Clermont-Ferrand, France

${ }^{\mathrm{b}}$ Department of Earth Sciences, Centre for Planetary Science and Exploration, University of Western Ontario, Ontario, Canada

${ }^{\mathrm{c}}$ Bayerisches Geoinstitut, Universität Bayreuth, Germany

*Corresponding author.

E-mail address: claudine.israel@uca.fr(C. Israel). 


\section{Supplementary 1.}

\section{Trace element patterns and $\mathrm{Ce}$ anomalies}

1. Trace element patterns

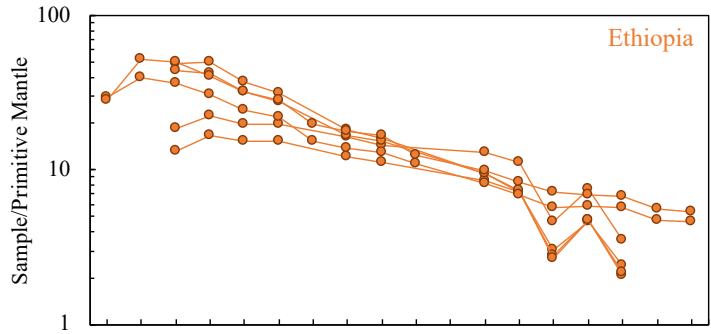

Th Nb La Ce Pr Nd Zr Sm Eu Ti Gd Tb Dv Y Ho Er Tm Yb

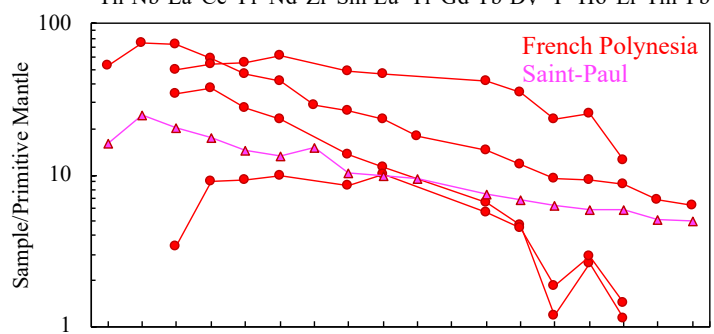

Th Nb La Ce Pr Nd Zr Sm Eu Ti Gd Tb Dy Y Ho Er Tm Yb

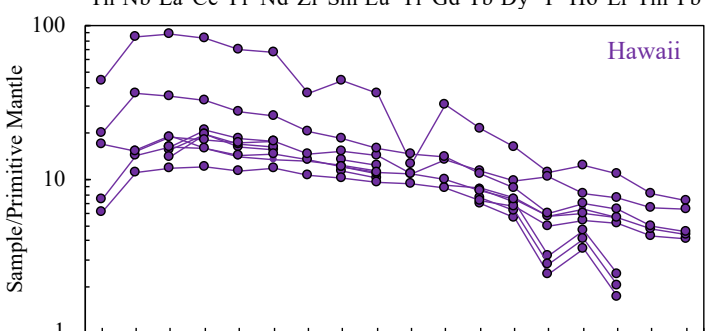

Th Nb La Ce Pr Nd Zr Sm Eu Ti Gd Tb Dy Y Ho Er Tm Yb

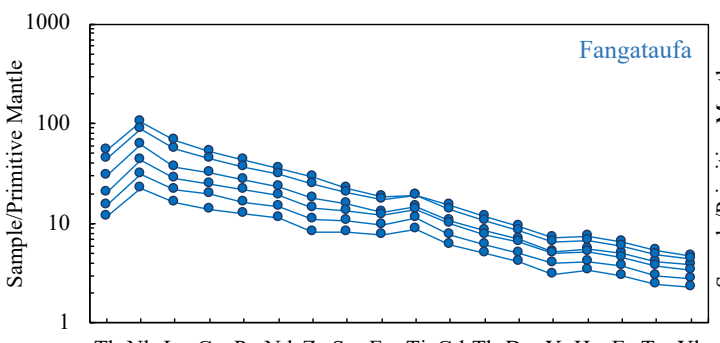

Th $\mathrm{Nb} \mathrm{La}$ Ce Pr Nd Zr Sm Eu Ti Gd Tb Dy Y Ho Er Tm Yb

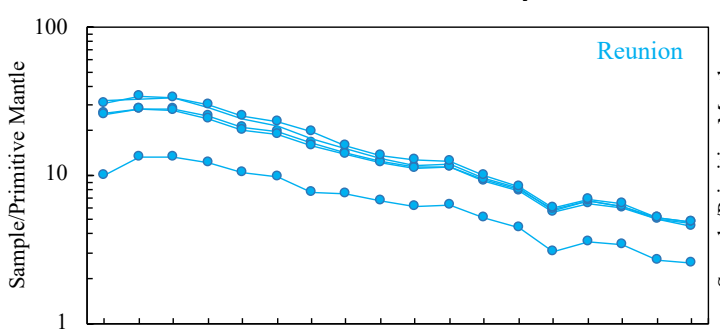

Th $\mathrm{Nb}$ La Ce Pr Nd Zr Sm Eu Ti Gd Tb Dy Y Ho Er Tm Yb

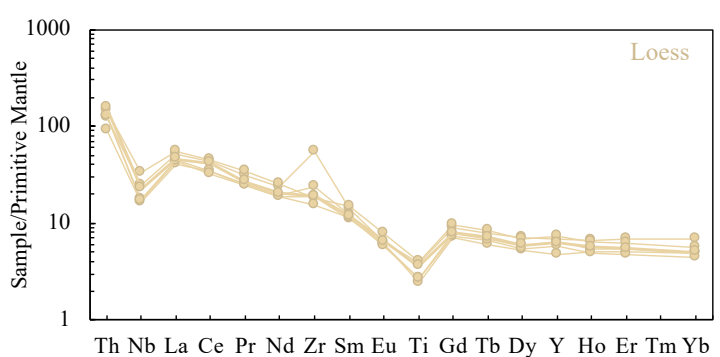

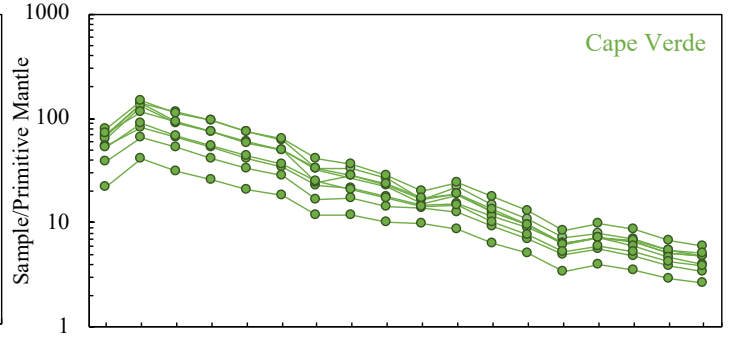

Th $\mathrm{Nb}$ La Ce Pr Nd Zr Sm Eu Ti Gd Tb Dy Y Ho Er Tm Yb$$
10
$$

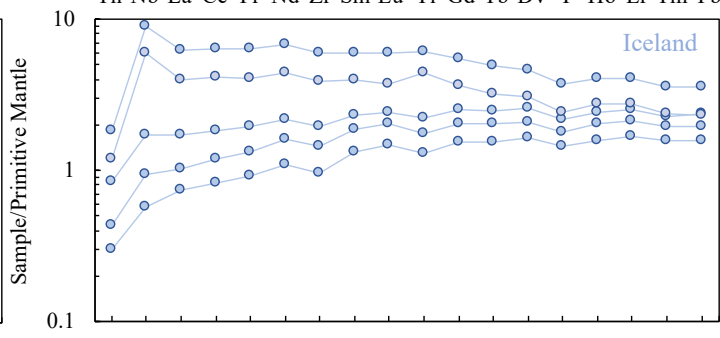

Th Nb La Ce Pr Nd Zr Sm Eu Ti Gd Tb Dy Y Ho Er Tm Yb

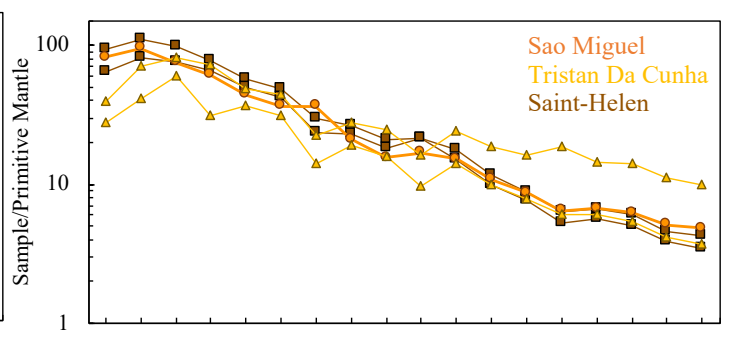

Th Nb La Ce Pr Nd Zr Sm Eu Ti Gd Tb Dy Y Ho Er Tm Yb

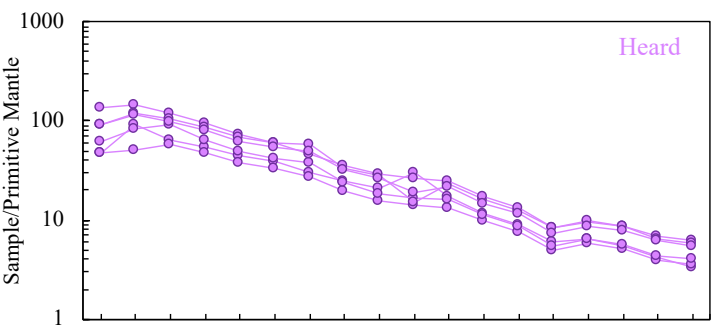

Th $\mathrm{Nb}$ La Ce Pr Nd Zr Sm Eu Ti Gd Tb Dy Y Ho Er Tm Yb

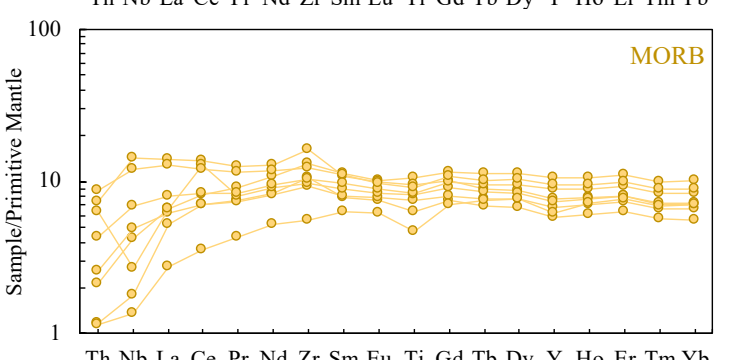

Fig. S1. Trace element patterns of OIBs, MORBs, and loesses. Concentrations are normalised to primitive mantle values (Sun and McDonough, 1989). 

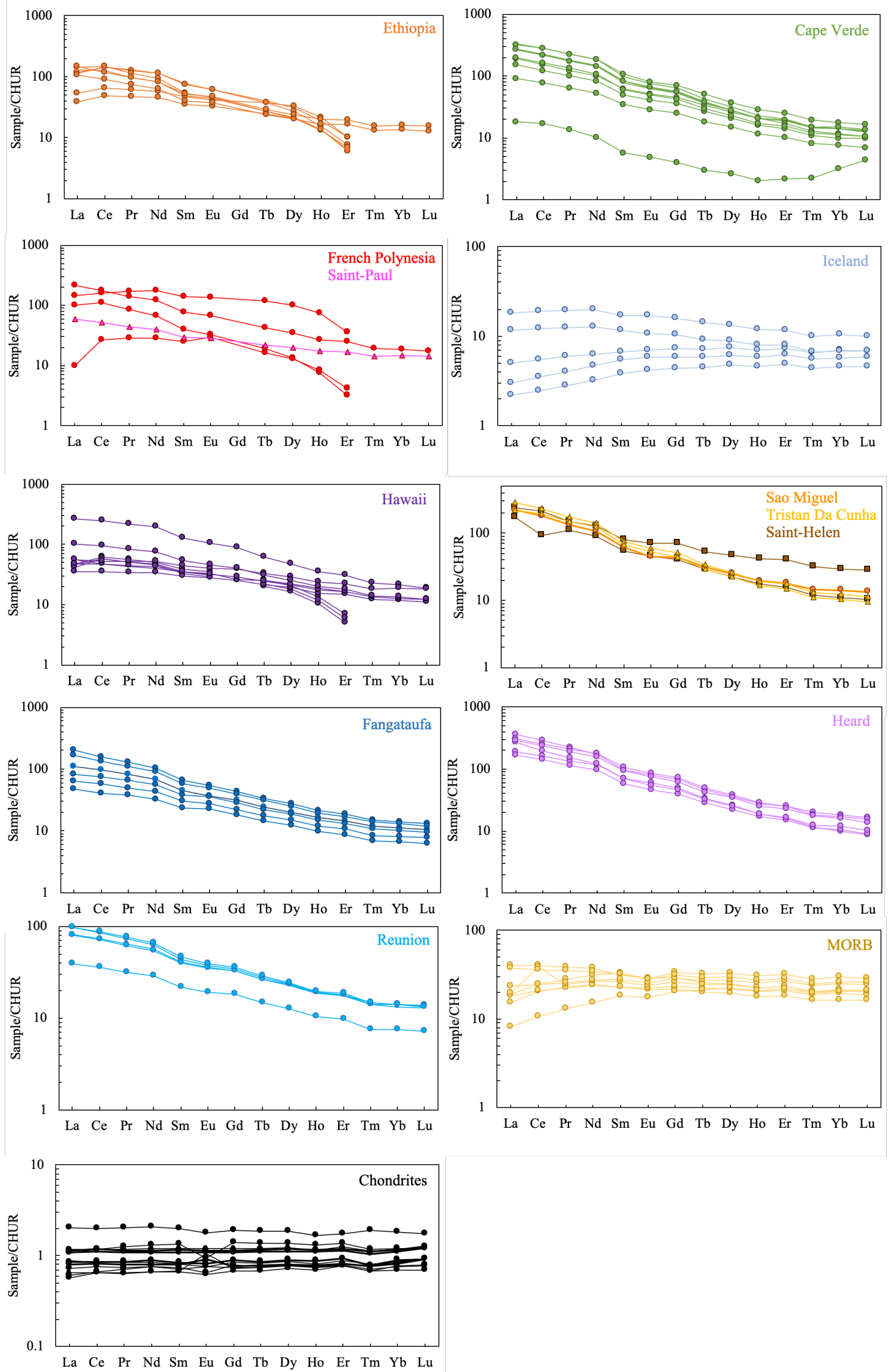

Fig S2. Rare earth element patterns of OIBs, MORBs, and chondrites. Concentrations are normalised to CI chondrite values (Barrat et al., 2012). 


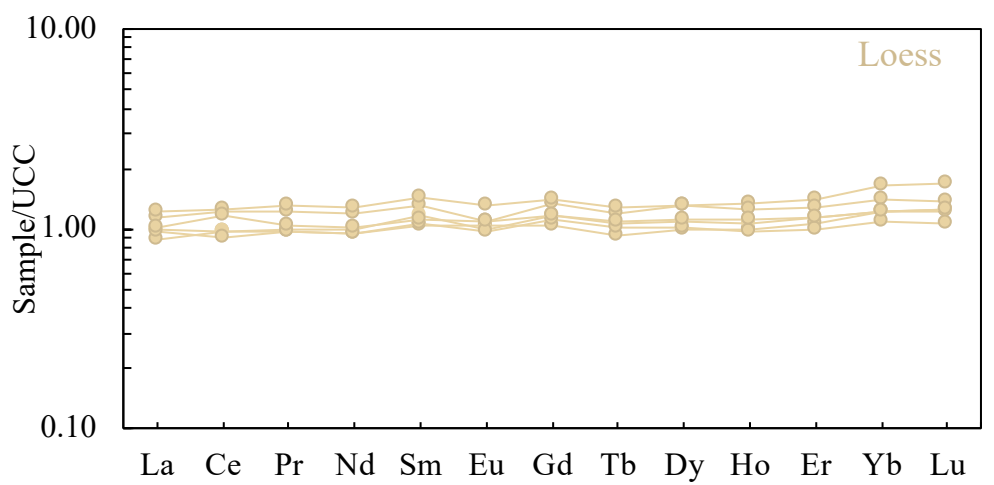

Fig. S3. Rare earth element patterns of loess samples. Concentrations are normalised to the upper continental crust (Rudnick and Gao, 2003).

2. Ce isotopic ratios as a function of elemental Ce anomalies

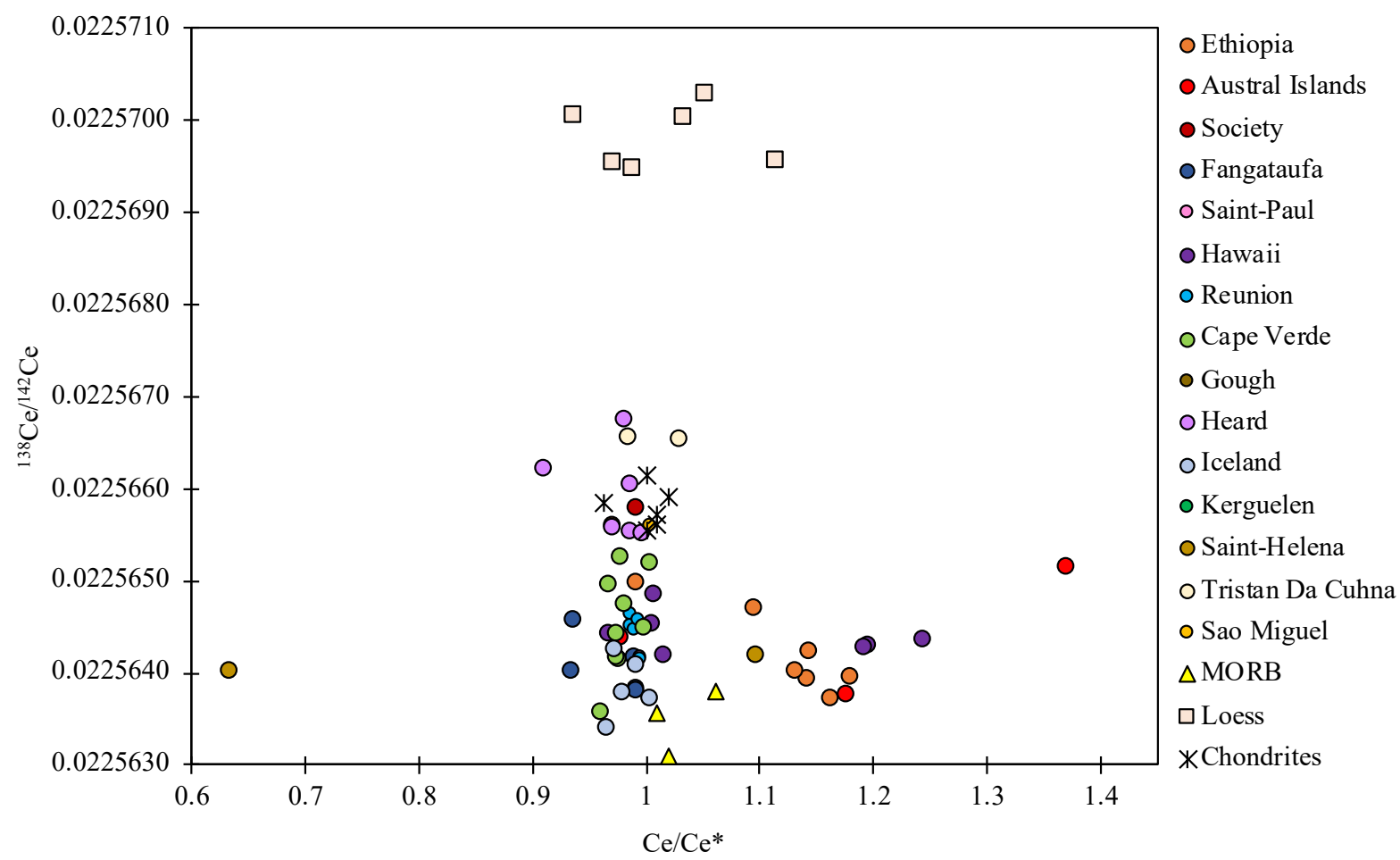

Fig. S4. ${ }^{138} \mathrm{Ce} /{ }^{142} \mathrm{Ce}$ vs $\mathrm{Ce} / \mathrm{Ce}$ * diagram for terrestrial samples analysed in this study. $\mathrm{Ce} / \mathrm{Ce}$ * represents the elemental $\mathrm{Ce}$ anomaly relative to the neighbouring REEs as $\frac{C e}{C e^{*}}=\frac{C e_{N}}{\frac{1}{2} L a_{N}+\frac{1}{2} P r_{N}}$, where $\mathrm{a}_{\mathrm{N}}, \mathrm{Ce}_{\mathrm{N}}$, and $\operatorname{Pr}_{\mathrm{N}}$ are the $\mathrm{La}, \mathrm{Ce}$, and $\operatorname{Pr}$ concentrations normalised to CI chondrite (Barrat et al., 2012). One sample from the Saint-Helena hotspot has a large negative Ce anomaly $\left(\mathrm{Ce} / \mathrm{Ce}^{*}=0.64\right)$, but its $\mathrm{Ce}$ isotopic composition is similar to that of other samples from the same location. This anomaly probably reflects the late alteration of the rock. Some samples from Ethiopia, Hawaii, and French Polynesia have significant positive anomalies. These anomalies reflect depletion in La (Fig. S2), and are not correlated with Ce isotopic ratios. 


\section{Supplementary 2.}

\section{Literature ${ }^{138} \mathrm{Ce} /{ }^{142} \mathrm{Ce}$ ratios and data normalisation: example with MORB}

We prefer to use the epsilon notation when comparing data from the literature. The most rigorous method for comparison is the use of CHUR values measured under the same analytical conditions (i.e., mass spectrometer, cup configuration, analytical protocol, etc.). This choice results from the difficulty in normalising data acquired with distinct protocols. In Fig. S5, we highlight the bias observed when comparing MORB samples from different studies (Bellot et al., 2015, 2018; Willig and Stracke, 2019)

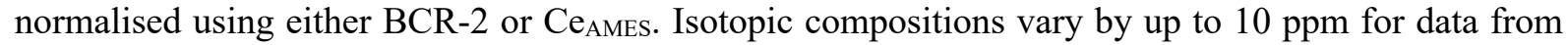
Willig and Stracke (2019) and by up to 20 ppm for data from Bellot et al. $(2015,2018)$.

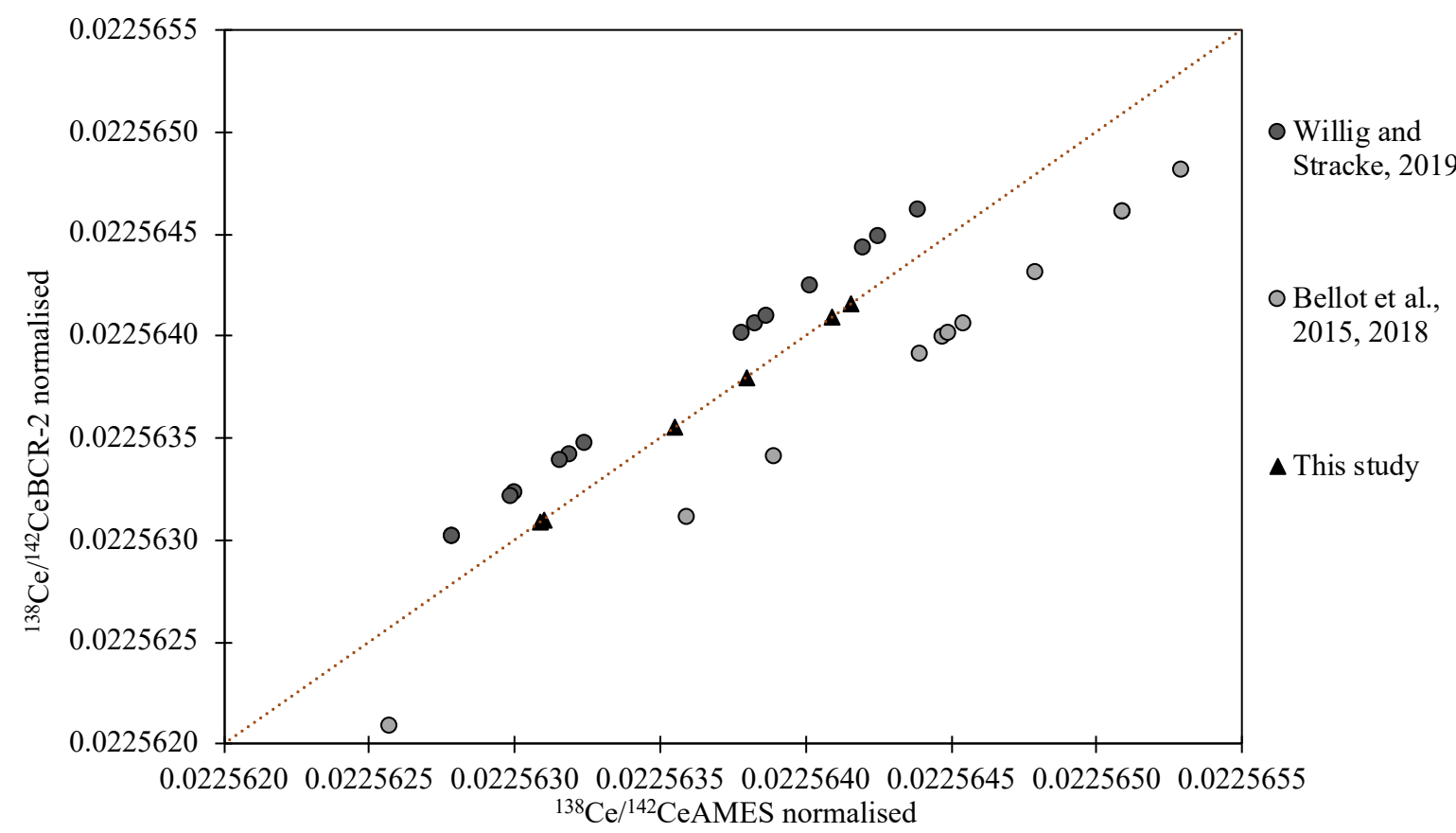

Fig. S5. Ce isotopic compositions of MORB samples from the literature normalised either to BCR-2 or to $\mathrm{Ce}_{\mathrm{AMES}}$ and compared to data from this study. The dotted line indicates the 1-1 correspondence line. 
Supplementary 3.

${ }^{138} \mathrm{Ce} /{ }^{142} \mathrm{Ce}$ ratios of crustal samples from literature

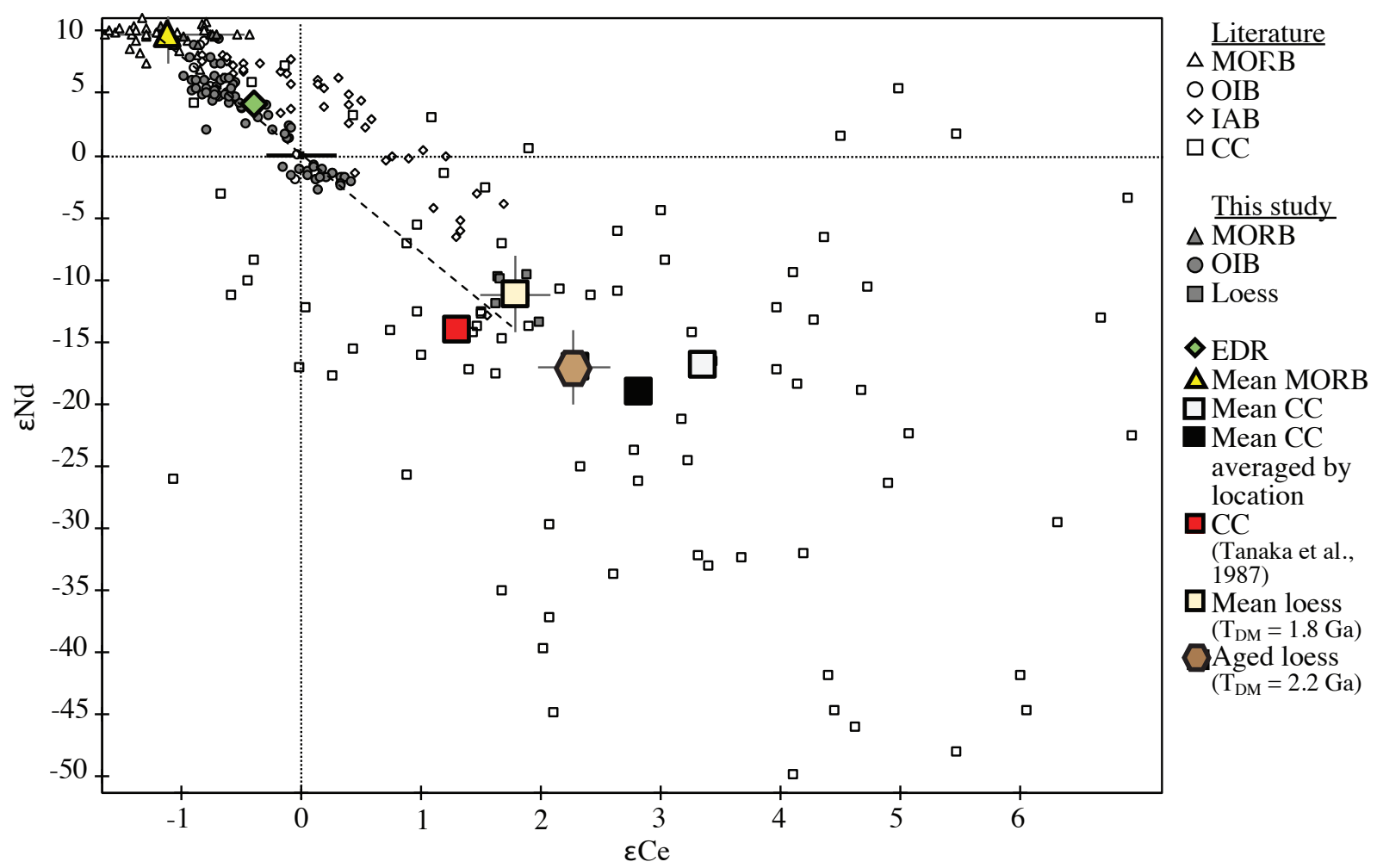

Fig. S6. ${ }^{143} \mathrm{Nd} /{ }^{144} \mathrm{Nd}$ vs ${ }^{138} \mathrm{Ce} /{ }^{142} \mathrm{Ce}$ ratios measured in mantle-derived samples (see Fig. 2) and continental crust samples (Dickin et al., 1987; Gao et al., 2016; Hayashi et al., 2004; Lee et al., 2001, 2010; Liu et al., 1990; Masuda et al., 1988; Minami et al., 1995; Shimizu et al., 1988, 1990, 1996; Tanaka et al., 1987; Tazoe et al., 2007). Large symbols represent reservoirs (as in Fig. 6). Note that the red square is the continental crust proposed by Tanaka et al. (1987). The black square is the mean value of all literature continental crust samples represented here $(n=94)$, and the open square is the mean continental crust value when samples are averaged by location $(n=16)$. 


\section{Supplementary 4.}

\section{Mass-balance DMM-CC mixing calculations}

Our single-stage differentiation model considers the continental crust (CC) and the depleted MORB mantle (DMM) to be complementary reservoirs developed from the primitive mantle (BSE).

The Nd sialic index $\left(W_{N d}\right)$ is defined as the amount of $\mathrm{Nd}$ in the continental crust relative to the total amount of Nd in the BSE (Allègre and Lewin, 1989). Its value can be obtained from the ${ }^{143} \mathrm{Nd} /{ }^{144} \mathrm{Nd}$ ratios of the BSE, DMM, and CC as:

$$
\frac{143 N d}{144 N d}_{B S E}=W_{N d} \times \frac{143 N d}{144 N d}_{C C}+\left(1-W_{N d}\right) \times \frac{143 N d}{144 N d}_{D M M} .
$$

The Nd sialic index can also be approximated as the product of the mass fraction of continental crust ( $W$, relative to the BSE) and the ratio of the $\mathrm{Nd}$ contents in the continental crust and BSE as:

$$
W_{N d}=W \times \frac{[\mathrm{Nd}]_{C C}}{[\mathrm{Nd}]_{B S E}} \quad \text { where } W=\frac{m_{c c}}{m_{C C}+m_{D M M}}
$$

Using $W$ as obtained above, the Ce sialic index $\left(W_{C e}\right)$ and the Ce isotopic composition of the continental crust can be deduced from equations similar to equations (1) and (2):

$$
\begin{aligned}
& W_{C e}=W \times \frac{[\mathrm{Ce}]_{C C}}{\left[\mathrm{Ce}_{B S E}^{\prime}\right.} \\
& \frac{138 C e}{142 C e_{B S E}}=W_{C e} \times \frac{138 C e}{142 C e_{C C}}+\left(1-W_{C e}\right) \times \frac{138 C e}{142 C e_{D M M}} .
\end{aligned}
$$

The mass fraction of continental crust $W$ also allows us to recalculate the complementary $\mathrm{Nd}$ and $\mathrm{Ce}$ contents of the DMM using mass-balance equations for the trace element concentrations:

$$
\begin{aligned}
& {[\mathrm{Nd}]_{B S E}=W \times[\mathrm{Nd}]_{C C}+(1-W) \times[\mathrm{Nd}]_{D M M},} \\
& {[\mathrm{Ce}]_{B S E}=W \times[\mathrm{Ce}]_{C C}+(1-W) \times[\mathrm{Ce}]_{D M M} .}
\end{aligned}
$$

To maintain a consistent dataset between isotopic and elemental ratios, the $\mathrm{Ce}$ and $\mathrm{Nd}$ concentrations of the DMM are recalculated using the BSE and CC contents and the mass fraction of DMM determined in step $2(=1-$ mass fraction of $\mathrm{CC}$ ). The $\mathrm{Ce} / \mathrm{Nd}$ ratio is set to 1.28 for a chondritic BSE and to 1.22 for the EDR model. So that the Lu value chosen to anchor the REE pattern of the BSE has no consequence on the final $\varepsilon \mathrm{Ce}$ value. Using the Lu contents proposed by Lyubetskaya and Korenaga (2007), Allègre et al. (2001), and Palme and O'Neill (2014) gives uncertainties of $\pm 0.3 \mathrm{ppm}$ on the Ce and Nd contents of the DMM. Corresponding DMM Ce and Nd concentrations are 0.1-1.0 and 0.6-1.0 ppm, respectively, in the chondritic case and 0.6-1.1 and 0.8-1.0 ppm, respectively, in the EDR model. We obtained restricted $\varepsilon \mathrm{Nd}_{\mathrm{CC}}$ ranges of -13 to -21 (CHUR) and -10 to -12 (EDR) that are similar within errors to the values proposed by Salters and Stracke (2004) and Workman and Hart (2005). 


\section{Supplementary 5. \\ Recycling models}
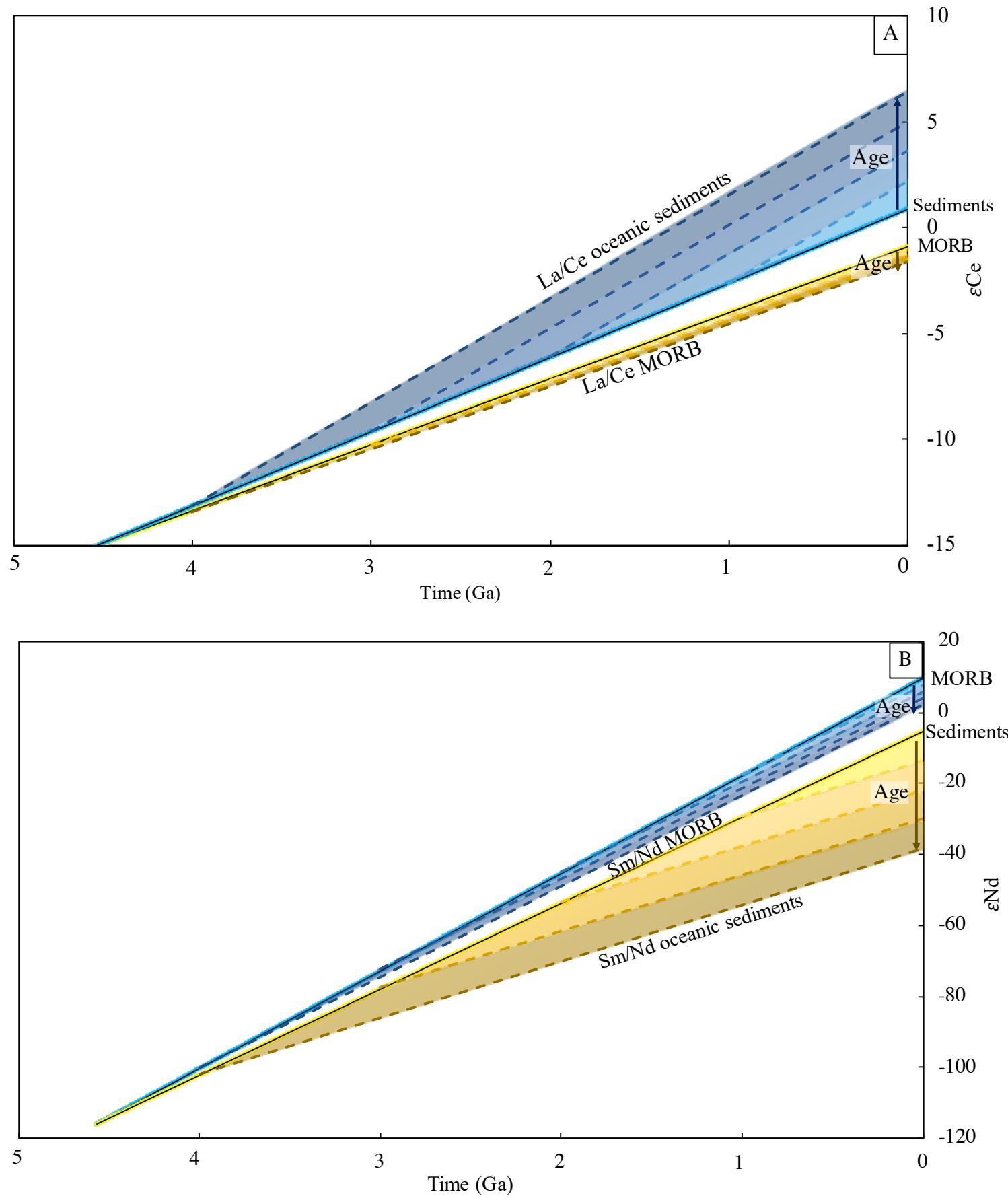

Fig. S7. Evolution models used to calculate the present (A) $\varepsilon N d$ and (B) $\varepsilon$ Ce isotopic compositions of recycled MORBs (yellow) and oceanic sediments (blue) for ages of formation between 4 and $1 \mathrm{Ga}$. Solid lines connect the present-day isotopic compositions of MORBs and oceanic sediments to the initial CHUR ratio, and dashed lines represent their isotopic evolution since the reservoir formation times. MORBs are characterised by $\mathrm{La} / \mathrm{Ce} \mathrm{MORB}_{\mathrm{M}}=0.34 \mathrm{and} \mathrm{\textrm {Sm }} / \mathrm{Nd} \mathrm{MORB}_{\mathrm{O}}=0.33$ (this study). Oceanic sediments formed after the Great Oxygenation Event are characterised by $\mathrm{La} / \mathrm{Ce} \mathrm{OS}=0.57 \mathrm{and} \mathrm{Sm} / \mathrm{Nd}$ OS $=0.20$ (data from Bellot et al., 2015, 2018), and those that formed earlier are assumed to have $\mathrm{La} / \mathrm{Ce}$ os $=0.47$ (after Ce anomaly

correction). MORB and oceanic sediments sources have constant chemical ratios extrapolated from the evolution of an initial chondritic reservoir until present-day composition. MORB source has $\mathrm{La} / \mathrm{Ce} \mathrm{MORB}_{\text {source }}=0.36 \mathrm{and} \mathrm{Sm} / \mathrm{Nd}_{\mathrm{MORB} \text { source }}=0.35$. Oceanic sediments source has $\mathrm{La} / \mathrm{Ce}_{\text {sediments source }}=0.41$ and $\mathrm{Sm} / \mathrm{Nd}_{\mathrm{MORB} \text { source }}=0.31$. Figure modified after Chauvel et al. (2008). 


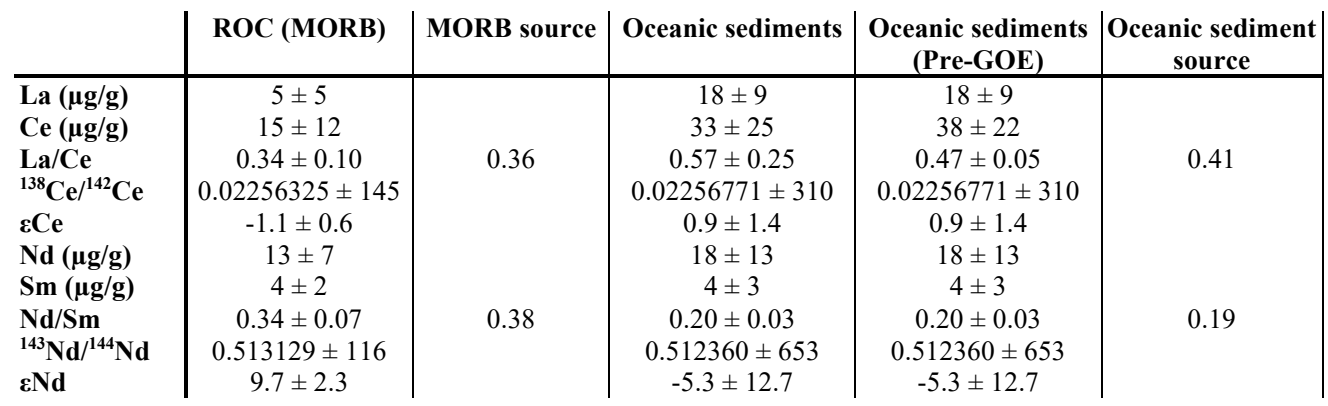

Table S1: $\mathrm{La}, \mathrm{Ce}, \mathrm{Sm}$ and $\mathrm{Nd}$ contents, $\mathrm{La} / \mathrm{Ce}$ and $\mathrm{Sm} / \mathrm{Nd}$ ratios and $\mathrm{Ce}$ and $\mathrm{Nd}$ isotopic compositions of terrestrial reservoirs used in recycling models (Fig. 5 and Fig. S7). ROC, recycled oceanic crust; DMM, depleted MORB mantle; GOE, great oxygenation event. ROC and oceanic sediments isotopic and chemical compositions are based on measurements (MORB: this study, Bellot et al., 2015, 2018, Makishima and Masuda, 1994 and Willig and Stracke, 2019; oceanic sediments: Bellot et al., 2015, 2018). ROC and oceanic sediments sources have constant chemical ratios extrapolated from the evolution of an initial chondritic reservoir until present-day isotopic compositions measured in MORB and oceanic sediments. Pre-GOE oceanic sediments $\mathrm{La} / \mathrm{Ce}$ ratio and $\mathrm{Ce}$ contents are corrected from Ce anomaly. 


\section{References :}

Allègre, C.J., Lewin, É., 1989. Chemical structure and history of the Earth: evidence from global nonlinear inversion of isotopic data in a three-box model. Earth Planet. Sci. Lett. 96, 61-88. https://doi.org/10.1016/0012-821X(89)90124-6

Barrat, J.-A., Zanda, B., Moynier, F., Bollinger, C., Liorzou, C., Bayon, G., 2012. Geochemistry of CI chondrites: Major and trace elements, and $\mathrm{Cu}$ and $\mathrm{Zn}$ isotopes. Geochim. Cosmochim. Acta 83, 79-92. https://doi.org/10.1016/j.gca.2011.12.011

Bellot, N., Boyet, M., Doucelance, R., Bonnand, P., Savov, I.P., Plank, T., Elliott, T., 2018. Origin of negative cerium anomalies in subduction-related volcanic samples: Constraints from Ce and $\mathrm{Nd}$ isotopes. Chem. Geol. 500, 46-63. https://doi.org/10.1016/j.chemgeo.2018.09.006

Bellot, N., Boyet, M., Doucelance, R., Pin, C., Chauvel, C., Auclair, D., 2015. Ce isotope systematics of island arc lavas from the Lesser Antilles. Geochim. Cosmochim. Acta 168, 261-279. https://doi.org/10.1016/j.gca.2015.07.002

Chauvel, C., Lewin, E., Carpentier, M., Arndt, N.T., Marini, J.-C., 2008. Role of recycled oceanic basalt and sediment in generating the Hf-Nd mantle array. Nat. Geosci. 1, 64-67. https://doi.org/10.1038/ngeo.2007.51

Dickin, A.P., Jones, N.W., Thirlwall, M.F., Thompson, R.N., 1987. A Ce/Nd isotope study of crustal contamination processes affecting Palaeocene magmas in Skye, Northwest Scotland. Contrib. Mineral. Petrol. 96, 455-464. https://doi.org/10.1007/BF01166690

Gao, Y., Ling, W., Qiu, X., Chen, Z., Lu, S., Bai, Xiao, Bai, Xiujuan, Zhang, J., Yang, H., Duan, R., 2016. Decoupled Ce-Nd isotopic systematics of the Neoproterozoic Huangling intrusive complex and its geological significance, eastern Three Gorges, South China. J. Earth Sci. 27, 864-873. https://doi.org/10.1007/s12583-016-0692-6

Hayashi, T., Tanimizu, M., Tanaka, T., 2004. Origin of negative Ce anomalies in Barberton sedimentary rocks, deduced from $\mathrm{La}-\mathrm{Ce}$ and $\mathrm{Sm}-\mathrm{Nd}$ isotope systematics. Precambrian Res. 135, 345-357. https://doi.org/10.1016/j.precamres.2004.09.004

Lee, S.-G., Asahara, Y., Tanaka, T., Kim, N.H., Kim, K.H., Yi, K., Masuda, A., Song, Y.S., 2010. La$\mathrm{Ce}$ and $\mathrm{Sm}-\mathrm{Nd}$ isotopic systematics of early Proterozoic leucogranite with tetrad REE pattern. Chem. Geol. 276, 360-373. https://doi.org/10.1016/j.chemgeo.2010.07.003

Lee, S.-G., Masuda, A., Shimizu, H., Song, Y.-S., 2001. Crustal evolution history of Korean Peninsula in East Asia: The significance of Nd, Ce isotopic and REE data from the Korean Precambrian gneisses. Geochem. J. 35, 175-187. https://doi.org/10.2343/geochemj.35.175

Liu, C.-Q., Shimizu, H., Nakai, S., Xie, G.-H., Masuda, A., 1990. Isotopic and trace element studies for Cenozoic volcanic rocks from western China: implication for a crust-like enriched component in the mantle. Geochem. J. 24, 327-342.

Masuda, A., Shimizu, H., Nakai, S., Makishima, A., Lahti, S., 1988. 138La $\beta$-decay constant estimated from geochronological studies. Earth Planet. Sci. Lett. 89, 316-322.

Minami, M., Shimizu, H., Masuda, A., Adachi, M., 1995. Two Archean Sm-Nd ages of 3.2 and 2.5 Ga for the Marble Bar Chert, Warrawoona Group, Pilbara Block, Western Australia. Geochem. J. 29, 347-362. https://doi.org/10.2343/geochemj.29.347

Rudnick, R.L., Gao, S., 2003. Composition of the continental crust, in: Holland, H.D., Turekian, K.K. (Eds.), Treatise on Geochemistry. Pergamon, Oxford, pp. 1-64.

Shimizu, H., Lee, S.-G., Masuda, A., Adachi, M., 1996. Geochemistry of Nd and Ce isotopes and REE abundances in Precambrian orthogneiss clasts from the Kamiaso conglomerate, central Japan. Geochem. J. 30, 57-69. https://doi.org/10.2343/geochemj.30.57

Shimizu, H., Nakai, S., Tasaki, S., Masuda, A., Bridgwater, D., Nutman, A., Baadsgaard, H., 1988. Geochemistry of $\mathrm{Ce}$ and $\mathrm{Nd}$ isotopes and REE abundances in the Amitsoq gneisses, West Greenland. Earth Planet. Sci. Lett. 91, 159-169.

Shimizu, H., Umemoto, N., Masuda, A., Appel, P.W.U., 1990. Sources of iron-formations in the archean isua and malene supracrustals, West Greenland: Evidence from La-Ce and sm-nd isotopic data and REE abundances. Geochim. Cosmochim. Acta 54, 1147-1154. https://doi.org/10.1016/0016-7037(90)90445-Q

Sun, S. -s., McDonough, W.F., 1989. Chemical and isotopic systematics of oceanic basalts: implications for mantle composition and processes. Geol. Soc. Lond. Spec. Publ. 42, 313-345. https://doi.org/10.1144/GSL.SP.1989.042.01.19 
Tanaka, T., Shimizu, H., Kawata, Y., Masuda, A., 1987. Combined La-Ce and Sm-Nd isotope systematics in petrogenetic studies. Nature 327, 113-117. https://doi.org/10.1038/327113a0

Tazoe, H., Obata, H., Gamo, T., 2007. Determination of cerium isotope ratios in geochemical samples using oxidative extraction technique with chelating resin. J. Anal. At. Spectrom. 22, 616. https://doi.org/10.1039/b617285g

Willig, M., Stracke, A., 2019. Earth's chondritic light rare earth element composition: Evidence from the Ce-Nd isotope systematics of chondrites and oceanic basalts. Earth Planet. Sci. Lett. 509, 55-65. https://doi.org/10.1016/j.eps1.2018.12.004 